Document of

The World Bank Group

Report No: 25440 AF

\title{
AFGHANISTAN
}

\section{TRANSITIONAL SUPPORT STRATEGY}

February 14, 2003

Afghanistan Country Management Unit

South Asia Region 


\title{
CURRENCY AND EQUIVALENTS
}

\author{
Currency Unit $=$ Afghani
}

US\$1 $=$ AFN44.567

FISCAL YEAR

21 March - 20 March (SY1381)

(Afghanistan uses a calendar based on the Persian or Islamic Solar Year (SY) which traditionally begins on or about
21st March.)

\section{ABBREVIATIONS AND ACRONYMS}

AACA Afghan Assistance Coordination Authority

AAA Analytical and Advisory Activities

ADB Asian Development Bank

AIA Afghan Interim Administration

ARTF Afghanistan Reconstruction Trust Fund

ASG

CAS

CDF

CG Consultative Group

FAO Food and Agriculture Organization

FMBA First Micro Finance Bank of Afghanistan

GDP Gross Domestic Product

IDA International Development Association

IFC International Finance Corporation

IFIs International Financial Institutions

IG Implementation Group

IMF International Monetary Fund

ISAF International Security Assistance Forces

$\begin{array}{ll}\text { JSDF } & \text { Japan Social Development Fund } \\ \text { MDGs } & \text { Millennium Development Goals } \\ \text { MIGA } & \text { Multilateral Investment Guarantee Agency } \\ \text { NDB } & \text { National Development Budget } \\ \text { NDF } & \text { National Development Framework } \\ \text { NGO } & \text { Non-Governmental Organization } \\ \text { NPV } & \text { Net Present Value } \\ \text { OECD } & \text { Organization for Economic Cooperation } \\ & \text { and Development } \\ \text { PCF } & \text { Post Conflict Fund } \\ \text { PPIAF } & \text { Public-Private Infrastructure Advisory } \\ & \text { Facility } \\ \text { PRSP } & \text { Poverty Reduction Strategy Paper } \\ \text { TA } & \text { Technical Assistance } \\ \text { TSS } & \text { Transitional Support Strategy } \\ \text { UN } & \text { United Nations } \\ \text { UNDP } & \text { United Nations Development Programme } \\ \text { UNICEF } & \text { United Nations Children's Fund } \\ \text { USAID } & \text { United States Agency for International } \\ & \text { Development }\end{array}$

$\begin{aligned} \text { Vice President: } & \text { Mieko Nishimizu } \\ \text { Country Director: } & \text { Alastair J. McKechnie } \\ \text { Country Manager: } & \text { William Byrd } \\ \text { Country Officer: } & \text { Mariam Sherman }\end{aligned}$

Country Officer:

\author{
Mieko Nishimizu \\ Mariam Sherman
}




\section{TRANSITIONAL SUPPORT STRATEGY}

\begin{tabular}{|c|c|}
\hline & Contents \\
\hline & EXECUTIVE SUMMARY.. \\
\hline I. & . \\
\hline II & BACKGROUND AND CURRENT SITUATION..... \\
\hline & A. Political and Security Developments - Progress Amidst Obstacles ............................................ 2 \\
\hline & B. Economic Situation - Signs of Progress \\
\hline & C. Public Administration - Resilient Structures but Weak Capacity ........................................... 5 \\
\hline & D. Reconstruction Funding and Implementation \\
\hline & 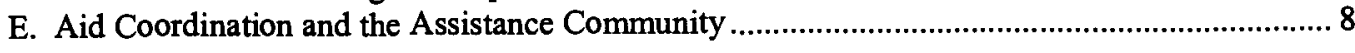 \\
\hline
\end{tabular}

III. IMPLEMENTATION OF THE BANK'S TRANSITIONAL SUPPPORT STRATEGY ............... 10

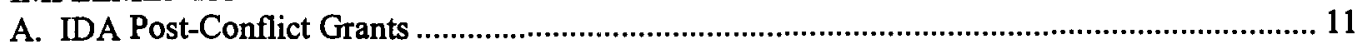

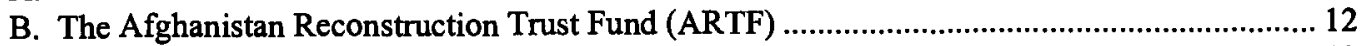

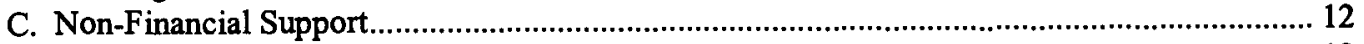

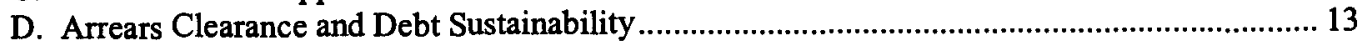

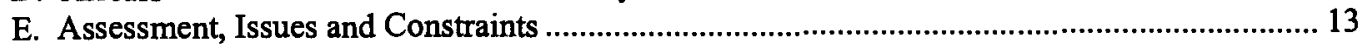

IV. THE GOVERNMENT'S RECONSTRUCTION STRATEGY …............................................. 17

V. THE WORLD BANK'S TRANSITIONAL SUPPORT STRATEGY …..................................... 19

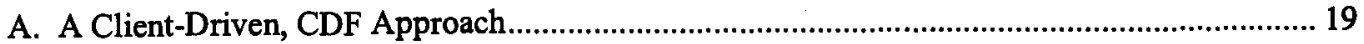

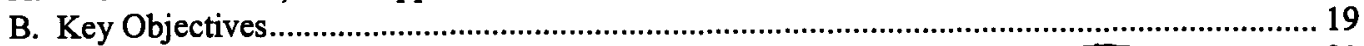

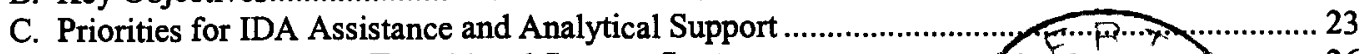

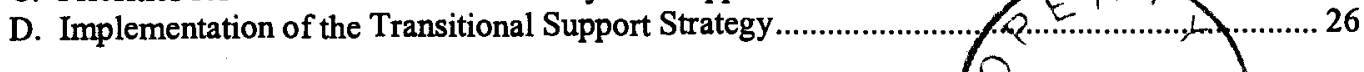

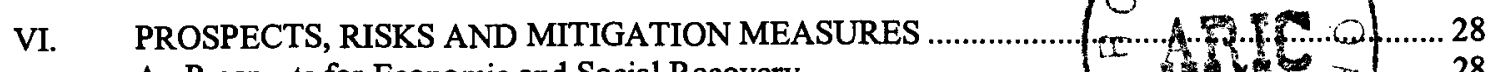

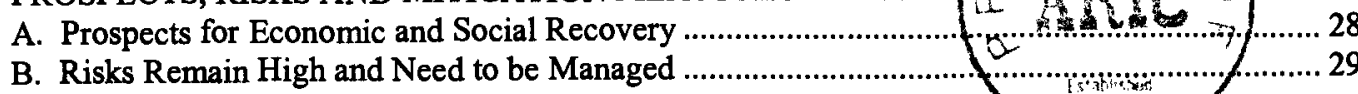

\section{BOXES}

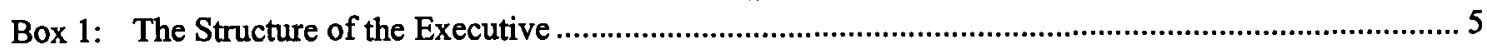

Box 2: Post Conflict Fund: The Basis for a Rapid Response ................................................................... 10

Box 3: IDA Funded Projects - Visible Results are Emerging................................................................. 11

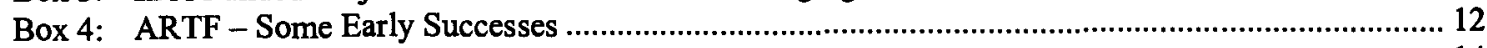

Box 5: Progress Toward Outcomes of the First TSS .............................................................................. 14

Box 6: The National Development Framework …….............................................................................. 18

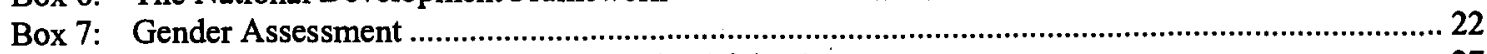

Box 8: Illustrative Benchmarks of Outcomes for Afghanistan ............................................................. 27

\section{ANNEXES}

ANNEX 1: Consultations on the World Bank's Transitional Support Strategy

ANNEX 2: The Structure and History of Public Administration

ANNEX 3: IDA Grant Funded Projects and Projects Under Preparation

ANNEX 4: Afghanistan and the Millennium Development Goals

ANNEX 5: The Establishment of Consultative Groups for Furtherance of the National Development Programs

ANNEX 6: Consultative Group Structure

ANNEX 7: The Post Conflict Fund

ANNEX 8: Afghanistan Reconstruction Trust Fund

ANNEX 9: The Twelve National Programs of Afghanistan's National Development Framework

ANNEX 10: Bank Group Program Summary FY02-FY04

ANNEX 11: International Finance Corporation's Strategy in Afghanistan 


\section{Afghanistan Transitional Support Strategy \\ Executive Summary}

i. Afghanistan is now at a critical point in its history where significant gains made in the past year and a half need to be consolidated, and the tangible benefits of development felt more widely by the Afghan people. Despite significant steps forward, the situation remains fragile with continued serious security problems encountered almost daily. Government security forces remain inadequate to widen state control and rein in disaffected groups around the country. The situation is further threatened by the possible negative repercussions of conflict in the broader region. Greater and more rapid progress in the reconstruction process will require continued, high-level attention and assistance from the international community.

ii. Political developments have proceeded well with the timely implementation of actions outlined in the Bonn Agreement, notably the formation of the Loya Jirga (Grand National Assembly), election of the President and establishment of the Transitional Government. Widely regarded as highly ambitious at the time, the rapid implementation of these actions bodes well for future progress. Nevertheless there is no room for complacency, and factional and ethnic tensions will continue to need to be addressed.

iii. On the reconstruction front, the Transitional Government of Afghanistan has elaborated a clear strategy for the country's reconstruction through its National Development Framework comprising twelve National Programs. Within this framework a government-led Consultative Group (CG) process is engaging with international assistance partners and making progress in aligning reconstruction programs with the country's development priorities and planning new programs on this basis. Based on principles of country-ownership and good governance, with a primary emphasis on the role of the private sector, the Consultative Group process has been well received by the international community. Yet ensuring benefits are felt in a timely manner by the entire population of Afghanistan, particularly by the poor and vulnerable, remains a major challenge.

iv. The Executive Directors may wish to discuss:

- The balance between strategic policy advice and financing immediate reconstruction needs;

- The alignment of the Bank's strategy with those of other development partners.

\section{World Bank Assistance - One Year On}

v. The first year of the Bank's re-engagement in Afghanistan has seen the preparation and implementation of four IDA Post Conflict grants totaling US $\$ 100 \mathrm{~m}$, and the establishment of the Afghanistan Reconstruction Trust Fund (ARTF) - a multi-donor fund with pledges to date exceeding US $\$ 200 \mathrm{~m}$ - that has become the main mechanism for funding recurrent costs of Government. In addition the Bank has established and staffed the World Bank office in Kabul.

vi. Initial Bank interventions focused on addressing urgent financial management and public administration needs to enable the Government to rapidly build capacity to oversee the reconstruction process. Other assistance provided invesiment funding for critical short-term priorities including education, infrastructure rehabilitation and job creation; focusing in many cases on opportunities for 'quick wins' due to prior investments or ability to quickly generate high returns. Policy advice and technical assistance have focused on demand-driven, specific and relevant inputs in key sectors including health, financial sector, private sector development and infrastructure. 
vii. The Bank's work in Afghanistan has benefited from the lessons of experience in other post-conflict countries, and from the analytical foundation laid through work funded by the Post Conflict Fund (PCF). It is notable that, reviewing achievements against goals set in the first Transitional Support Strategy (TSS), progress has been very good. A careful review of experience in Afghanistan to date provides valuable lessons to guide future work. More specifically, progress might have been more rapid had some constraints, for example fundamental issues such as payments systems, been better anticipated and addressed from the beginning.

\section{The Transitional Support Strategy - A Comprehensive Development Framework Approach}

viii. The reconstruction strategy developed by the Government forms the framework within which this Transitional Support Strategy has been prepared. Developed in consultation with the Government and other stakeholders, the Transitional Support Strategy puts forward priorities for Bank financial and non-financial assistance based on the areas of comparative advantage of the Bank and where other donors are engaged, in line with a Comprehensive Development Framework (CDF) approach. This strategy, which also begins the transition from a short-run emergency orientation to a longer-term development orientation, covers a period of 18 months to two years, until Afghanistan's new Constitution is promulgated and a stable, representative government is established. At that time it is anticipated that the Government would start work on a Poverty Reduction Strategy Paper (PRSP), and work on a Country Assistance Strategy (CAS) will be initiated.

ix. The Bank will focus on four strategic areas: (a) improving livelihoods; (b) fiscal strategy, institutions and management; (c) governance and public administration reform; and (d) enabling private sector development.

x. Following the clearance of Afghanistan's arrears to IDA, the Bank anticipates presenting up to four new IDA operations in FY03, and additional operations in FY04, to fully realize the World Bank's Tokyo pledge totaling US\$570 million (of which US\$100 was committed in FY02 in the form of IDA Post-Conflict Grants). The Bank will continue, through timely and relevant analytical work and technical assistance, to address key areas of reform such as public administration and creating an environment conducive to private sector development, without which reconstruction investments are unlikely to be fully successful. The Bank anticipates that it will not provide major new financial assistance in three areas where it is currently engagedhealth, education and transport-beyond activities already at an advanced stage of preparation. This consolidation takes into account the need for selectivity and strong donor interest in these areas

xi. Prospects for economic and social recovery will continue to depend on both improvements in security and continued consolidation and enhancement of the Government's role. Initial signs of economic recovery and actions taken by the Government to date illustrate that significant gains can be made if peace and stability take hold. The continued lack of security and sporadic fighting around the country remain significant cause for concern. Moreover, heightened tensions associated with a possible war in Iraq cannot be overlooked and raise the additional serious concern of diversion of attention of countries currently supporting the reconstruction process. In this context, the strong longer-term commitments made both in Tokyo in January 2002 and more recently in the Afghanistan Support Group meeting in December 2002 are reassuring but need to be implemented. 


\section{INTRODUCTION}

1. Slightly more than a year has passed since the signing of the Bonn Agreement (December 5,2001 ), which set a roadmap for securing peace and political normalization in Afghanistan, and the installation of the Afghan Interim Administration (AIA) (December 22, 2001) which began the process of rebuilding a legitimate Afghan state. It has been nine months since the Emergency Loya Jirga elected Hamid Karzai as Afghanistan's Head of State and the Transitional Government was installed.

2. World Bank re-engagement with Afghanistan, after a gap of more than two decades, began in earnest with the Preliminary Needs Assessment prepared jointly with the United Nations Development Program (UNDP) and the Asian Development Bank (ADB) during December 2001 - January 2002, followed by a number of joint sector missions (February-June 2002), preparation of the first Transitional Support Strategy (TSS) (March 2002), approval of IDA Post-Conflict Grants (one in April and three in June), and establishment of the World Bank's Kabul Office (inaugurated by Mr. Wolfensohn on May 15, 2002). More recently the arrears of IDA, ADB, and IMF have been cleared within a coordinated framework, which enables normal IDA financial assistance to Afghanistan to go ahead under the IDA-13 replenishment.

3. In the period since the Bank's first TSS for Afghanistan was prepared, the Government has put forward a compelling vision and strategy for national reconstruction embodied in its National Development Framework (April 2002), and at the same time promulgated the recurrent budget for the Afghan Fiscal Year 1381 (March 2002 - March 2003). More recently, progress has been achieved by the Government in preparing the National Development Budget for fiscal years 1381 and 1382, and in moving to a government-led Consultative Group process for aid coordination. The Government's recurrent budget for the current Afghan financial year has been adequately funded after some initial difficulties, and the currency reform has been successfully completed.

4. On the other hand, security remains a serious obstacle to the delivery of reconstruction assistance and effective implementation of reconstruction programs; Afghanistan's poverty level and social indicators remain among the worst in the world; capacity in the Government remains weak despite improvements; and the pace of implementation of reconstruction has fallen short of government and popular expectations.

5. Thus now is a good time to take stock of the progress achieved so far, to review the lessons from experience with early World Bank financial and non-financial assistance to post-conflict Afghanistan, to fully align our strategy with the Government's vision and national strategy for reconstruction, to prioritize our activities in line with the Bank's comparative advantages taking a Comprehensive Development Framework approach; and to identify key challenges and ways to address them. Moreover, it is also time to begin to make the transition from an emergency orientation that to a large extent characterized the first TSS, to a longer-term developmental approach.

6. The strategy presented in this document is expected to cover the remaining 18-month to two-year period until Afghanistan develops a new Constitution and a stable, representative government is put in place under the new constitutional arrangements. Once these key milestones in the political process mandated by the Bonn Agreement are passed, it is anticipated that Government would begin work on a PRSP and work on a Country Assistance Strategy could be initiated. The TSS will be kept flexible and refined as developments require. The strategy outlined in this document has been enriched by inputs received through a series of consultations 
held in Kabul in January 2003 with representatives of Government, donors, UN agencies, civil society and the private sector (Annex 1).

7. This document first provides background information and summarizes the current situation and status of the overall reconstruction effort. Section III provides an assessment of the progress achieved under the first TSS for Afghanistan - achievements, failures, lessons learned, and key challenges for the future. Section IV reviews the Government's reconstruction strategy and approach to implementation, as detailed in the National Development Framework and other Government documents. Section V presents the Bank's TSS for Afghanistan, including its objectives, strategic focus, cross-cutting themes, and implementation approach, and Section VI highlights prospects and risks for the future.

\section{BACKGROUND AND CURRENT SITUATION}

\section{A. Political and Security Developments - Progress Amidst Obstacles}

8. Afghanistan faces a complex political situation and difficult security issues. Without adequate security and steady progress toward political normality as stipulated in the Bonn Agreement, the prospects for Afghanistan's reconstruction and longer-term poverty reduction and economic development would be weak. Considerable progress has been achieved especially on the political front, but daunting challenges remain.

9. The Bonn Agreement established an ambitious timetable for political normalization, with a number of key benchmarks. During the period covered by the first TSS, these benchmarks included most notably the following:

- Holding of the Emergency Loya Jirga, selection of the Head of State and other leaders, and formation of a Transitional Administration to guide the country until a permanent government is formed.

- Establishment of a Judicial Commission, Human Rights Commission, and Civil Service Commission.

- Formation of a Constitutional Commission and drafting of a new Constitution to be promulgated by December 2003.

- Preparations for holding nationwide elections by June 2004 to elect a fully representative, stable government under the new constitutional arrangements.

- Progress toward formation of a national army to take over from the myriad regional forces and militias previously operating in Afghanistan.

10. Although these targets were widely considered to be ambitious and difficult to achieve within the allotted time frame, it is notable that key benchmarks under the Bonn Agreement so far have been achieved almost in their entirety and on time.

11. The Transitional Government, which was formed as an outcome of the Emergency Loya Jirga, has continued to improve the quality of governance and decision-making. Progress has been slower in the substantive work of some of the independent Commissions and in formation of a truly national army, and work on the Constitution and elections has only just begun. Nevertheless, Afghanistan is to be congratulated on the political progress achieved, which has exceeded general expectations. 
12. There is no ground for complacency however. The political benchmarks for the period covered by this TSS are even more ambitious than the targets achieved so far. Work on the new Constitution and on elections will be difficult and delicate. The formation of the national army requires a great deal of attention. Ethnic and factional divisions remain significant and could erupt or block political progress. And it is only natural that there are uncertainties about the final political shape that Afghanistan will take based on its people's decisions.

\section{Security remains a critical constraint to Afghanistan's reconstruction and economic} progress. There are a number of elements:

- The military and prevention of widespread armed conflict

- Disarming, demobilizing, and re-integrating combatants

- Law enforcement (police)

- Judicial system

- Crime

- Ethnic tensions

- Drugs

- Landmines

14. Security has improved in a number of respects. First and most important, resurgence of major civil conflict has been avoided although there are concerns about the possibility of renewed fighting in the spring. Sporadic outbreaks of armed conflict, even if not always fully resolved, have been contained and prevented from spreading; and many have been resolved through negotiations facilitated by the central government. Second, the internationally sponsored security arrangements for Kabul, based on the International Security Assistance Forces (ISAF) in cooperation with Afghan security forces, have worked reasonably well. Third, some improvements have been made in the police in some parts of the country, and the first units of a national army have been formed and trained. Fourth, security on the main intercity roads of Afghanistan has improved significantly compared with the situation in late 2001 and early 2002. And fifth, progress has continued in the massive effort to rid Afghanistan of landmines, based on the largely indigenous de-mining capacity developed over the past 10 years.

15. Set against these achievements, there have also been some setbacks. Opium poppy cultivation, which had been sharply reduced during 2000 and especially in 2001, made a strong comeback in 2002, and cultivation has further expanded in the 2003 season. Narcotics production and trade, and the profits from these activities, constitute a major threat to Afghanistan's security, political normalization, and economic development. Containment and, over time, eradication of illicit drug production inevitably will be a long-term effort, requiring a combination of effective law enforcement (both domestic and international) and rural development generating alternative livelihoods.

16. Progress in improving security outside Kabul and in extending the reach of the national government into the provinces has been uneven. In addition to the continuing threat of instability from several quarters, Afghans are concerned about ordinary crime, although data are not reliable enough to ascertain whether crime has been increasing. Dealing with crime will require an effective judiciary and law enforcement and providing real opportunities for education, training and employment. It will also be important to demobilize and re-integrate into society the many combatants that will not find a place in the national army, who otherwise might well be attracted into criminal activities. 
17. Despite a request from the Government (endorsed by other stakeholders), it was not possible to expand ISAF to other cities. The Government, lacking the ability to widen state control and rein in disaffected groups across the country, has had to deal with regional authorities from a weaker position than otherwise would have been desirable. Nevertheless, a combination of positive and negative incentives, bolstered in many areas by a fundamental popular perception of the legitimacy of the national government, has enabled some progress to be made, although there is a long way to go.

18. All in all, security remains fragile and in many parts of the country problematic. The security situation will continue to constrain the progress of reconstruction, and security concerns may continue to discourage foreign and large-scale domestic investment. Thus improving security will continue to demand high priority, attention, and resources from the Afghan Government and its partners. Of particular importance will be the effort to build a truly national army and disarm and reintegrate other combatants, and to develop an effective, rights-sensitive police force.

\section{B. Economic Situation - Signs of Progress}

19. GDP is likely to have grown by about 10 percent during the past year from a base of around $\$ 4$ billion. ${ }^{1}$ While lack of data for recent years makes this a tentative estimate, a sharp rebound in economic activity from the very depressed level of the previous year should be expected. Construction and service sectors have benefited from a gradual recovery in confidence, the return of refugees, and external assistance inflows. Agricultural prospects also improved with greater security and with good precipitation and recovery from drought in many areas. However, even with this level of growth, GDP per capita would still only reach the range of $\$ 175$ to $\$ 220$, placing Afghanistan among the poorest countries in the world.

20. The short-term demand stimulus provided by reconstruction assistance needs to be translated into robust, sustainable economic growth. For this, Afghanistan will need peace and security. It will need to look toward sustainable agricultural (non-poppy) growth. Small-scale entrepreneurship and business activities need to expand to create jobs. Furthermore, opportunities for trade and regional development, if realized, would also be a growth driver.

21. Since the last TSS, the Government has prepared a recurrent budget for the Afghan fiscal year 1381 (March 2002-March 2003). The Government has also prepared a rudimentary development budget that will be improved over time. While budget execution was initially slow (both in terms of revenues and expenditures), it has now accelerated. The Afghan Government plans to report to donors on budget execution in the second half of March when they present next year's budget. Early indications point to exceeding revenue targets and coming close to budgeted recurrent expenditures. Next year, earlier donor funding commitments to close the budget gap will help the Government plan and smooth budget execution over the entire year. In terms of reporting, the authorities have computerized the Treasury accounting system and are now in a position to compile timely reports on budget execution of the payroll and spending by ministries that takes place in Kabul, although reporting on spending at the provincial level is still relatively weak.

22. A major currency conversion has been successfully completed, with AFN1 new equal to AFN1,000 old. Some implementation difficulties were inevitable, and this led to pressure on the

1 These estimates exclude illegal poppy cultivation and narcotics production. 
Afghani, which fell to an exchange rate of over AFN70,000 per US dollar in early November 2002 compared to under AFN40,000 per US dollar in late August 2002. However, by January 2003 the authorities had dealt with most of the bottlenecks, pressure on the Afghani eased, and the exchange rate has now stabilized in the range of AFN45,000-50,000 (AFN45-50 for the new currency) per US dollar.

23. Over the past year, the Government has maintained a conservative fiscal and monetary policy stance. Exchange rate movements have been the main driver of inflation, with significant spikes of deflation and inflation mirroring appreciation and depreciation of the currency. As the Afghani stabilizes, it will be easier to monitor any inflationary impact of donor inflows.

\section{Public Administration - Resilient Structures but Weak Capacity}

24. A functioning and efficient government structure that is able to reach out effectively across the country is essential for the success of the reconstruction process and longer-term development of Afghanistan. Despite years of neglect and war, there is evidence of resilience in the public administration structure.

25. Formally, Afghanistan is a unitary state with a remarkable degree of centralization, administratively and fiscally. In principle, the relationship between subnational entities and Kabul is one of very modest deconcentration. The structure of the state has as its basis a number of fiscal and administrative arrangements put in place in the late $19^{\text {th }}$ century (Box 1 and Annex 2) which bound the districts and provincial capitals to Kabul, forming a highly centralized state.

26. Three decades of war have not led to complete state collapse. They certainly led to the collapse of legitimate political authority, and the de facto usurpation of political authority by local commanders and warlords, but the fiscal and administrative arrangements still provide a glue that has held the state together in many respects.

27. Reconstructing the State - building on strengths: Afghanistan has three key strengths that can be capitalized on in rebuilding the public sector.

- The administrative laws are sound. The existing Budget Law and Accounting Regulations, while somewhat complex, are sound, with appropriate checks and balances. The Budget Law provides some elements of very good practice, in particular in its requirement that the full costs of projects should be reflected in the Government's Budget. The Control and Audit Law makes the General Control and Inspection Department of the Council of Ministers the supreme audit authority for the whole of government, providing external audit.

- The underlying arrangements for government employment stem from basically sound legislation which provided for a system of centralized recruitment, and established a system of job classification and grading that provides the underpinning for managing pay policy within the public sector. 
- These laws are well understood and are followed. Primary responsibility for implementing the Budget Law lies with the Ministry of Finance in Kabul and the network of provincial agents of the Ministry in the Provinces-Mustoufie Velayat (also known just as Mustoufie). However, the overall state of telecommunications is appalling and is contributing very significantly to problems in the existing system.

28. According to recent national employment data, the public sector is not bloated. Public employment is, in absolute terms, relatively small, at between 0.8 percent and 1.4 percent of the assumed population of 23 million $^{2}$ (see Annex 2). However, this must be seen in the context of the lack of effective government-relative to its capability, this is not a small government. A large proportion (around 40 percent) of this relatively small workforce is located in Kabul. ${ }^{3}$ Current salary levels, with average pay of around $\$ 40$ per month, and very little differentiation in pay between the top and bottom grades, present serious problems if experienced and qualified professionals are to be attracted and retained in the public sector.

29. Afghanistan's fiscal system is highly centralized in structure, but domestic revenues have been for the most part retained by regional authorities and need to be re-centralized. The focus of concern is customs, where there have been operational difficulties and significant political problems with remitting customs revenues to Kabul. More generally, there is a need to progressively increase mobilization of domestic revenues and their accrual to the national government, which comprises an essential element of state-building and also is required to reduce current high levels of external financing of government recurrent budgetary expenditures over time. The Government is initiating reforms in customs which are of high priority and will need to include both legislative and procedural changes.

30. The key principle that must underpin all assistance to the public sector is to work with the strengths of the system, nurturing the discipline that has remained despite the many years of conflict. This means respecting and strengthening the budget process as the central vehicle for coordinating and communicating government policy, and supporting the management structures and the authority of ministers and their senior staff. Supporting management structures also means avoiding the distracting impact of uncoordinated salary top-ups and incentive payments. In the health sector in particular, poor pay for doctors and other health professionals has already led to a proliferation of top-ups from donor agencies and NGOs. When staff receive incentive payments from NGOs and others that are far larger than their public sector salaries, this creates serious management difficulties.

31. The Bank is supporting a number of policy reform priorities through the Emergency Public Administration Project and technical assistance (Annexes 2 and 3), including improving the quality of budget preparation and accelerating its execution, particularly in the provinces;

2 In recent years, general civilian government employment (i.e. public sector employment excluding the military and excluding state owned enterprises) has accounted for about 2.5 percent of the population in Asia and the Pacific. The estimates of employment for the provinces are not disaggregated between sectors and thus the data do not allow any assessment to be made on the proportion of public sector employment that is in the social sectors (education, higher education and health). 40 percent is typical except for the Former Soviet Union where social sector employment averages at around 70 percent of general civilian government.

This is potentially problematic as it suggests that any moves towards adequate staffing in the provinces without corresponding reductions in staff in Kabul could produce a large government, which would be both unnecessary and unsustainable. It will not be easy to persuade existing staff to leave Kabul and work elsewhere. 
ensuring timely payment of salaries; promoting fiscal transparency; and supporting efforts to reform public administration.

\section{Reconstruction Funding and Implementation}

32. Overall funding picture: Donor pledges for 2002 totaled approximately US $\$ 2.1 \mathrm{bn},{ }^{4}$ with commitments reaching US\$1.95bn, of which approximately 72 percent has been disbursed. A breakdown between activities of the majority of disbursed funds (US\$1.3 billion) indicates that US $\$ 195 \mathrm{~m}$ went to supporting the Government and direct budget support, US $\$ 630 \mathrm{~m}$ to humanitarian and relief efforts, and US $\$ 420 \mathrm{~m}$ to reconstruction, with the remainder supporting coordination and logistics for the delivery of aid (approximately $\$ 50 \mathrm{~m}$ ) and support to Afghan refugees outside the country (approximately $\$ 20 \mathrm{~m}$ ). It should be noted, however, that in reality it is difficult to disentangle reconstruction and development activities from humanitarian initiatives, and moreover, the Afghan Assistance Coordination Authority (AACA) reports that much reconstruction assistance is in fact for emergency short-term purposes.

33. Commitments specifically to reconstruction fell short of the $\$ 1.7 \mathrm{bn}$ assessed as needed for the first year of the reconstruction program. ${ }^{5}$ Moreover, subsequent reviews indicate that reconstruction needs could be much higher, particularly as many of the funds pledged for reconstruction have supported humanitarian assistance. Commitments of support for the Government's operating budget, despite a slow start, have increased significantly and have to a large extent closed the Government's deficit for the current fiscal year, with the Afghanistan Reconstruction Trust Fund (see page 12) serving as the main instrument to fund recurrent costs. The largest shortfall in commitments has been in the area of reconstruction investment, constrained by a shortage of "bankable" government-sponsored projects and by delivery systems which, unlike in the case of humanitarian programs, have only recently begun operating again in Afghanistan.

34. Turning to tangible results on the ground, there have been some important achievements, including:

- a doubling in school enrollment as compared to forecasts, with 3 million children enrolled in the current school year compared with 1.5 million in early 2002, primarily as a result of the UNICEF-supported Back-to School Campaign;

- an unexpectedly high proportion of female enrollment-30 percent of the enrolled children are female;

- an increase in vaccination efforts with NGO-supported polio vaccination now reaching more than 6 million children;

- widespread distribution of vitamin A underway;

- in Kabul 5,000 water supply household connections have been repaired, over 200 schools and 15 hospitals/clinics have been repaired, and piped water capacity has more than doubled since June 2002;

\footnotetext{
${ }^{4}$ Data provided by the Afghan Assistance Coordination Authority (AACA), Aid Coordination Unit and is based on information provided by donors. Further details are available in the Donor Assistance Database: $\mathrm{http}$ ://aacadad.undp.org. Breakdown of use of disbursed funds is based on most recent available information from October 2002.

${ }_{5}^{5}$ The Preliminary Needs Assessment conducted by the World Bank, the ADB and the UNDP, identified the need for approximately $\$ 1.7 \mathrm{bn}$ to be committed during the first year toward reconstruction investments and government recurrent costs. The Transitional Government's Development Budget process suggests even higher requirements.
} 
- modest improvements have occurred in access to small-scale infrastructure such as water supply and irrigation, and employment opportunities have been created in rural areas across the country through various public works programs;

- agriculture has rebounded, with food production increasing by an estimated 82 percent.

35. But results still fall far short of meeting the enormous needs of the Afghan people:

- jobs need to be created in the short-run to support livelihoods of returning displaced families, ex-combatants, and vulnerable people more generally;

- life expectancy, at 43 years, is one of the lowest in the world and, in terms of the MDGs, Afghanistan ranks very low (Annex 4);

- access to basic services is also extremely limited with only 23 percent of the population having access to safe water and 12 percent to adequate sanitation;

- despite increases, female enrollment remains a challenge with rates standing at only 10 percent in some provinces;

- more than 70 percent of schools are estimated to need repairs;

- despite improvements in the business climate, investors are still very cautious about making large investments in Afghanistan.

36. A critical objective at this point is to build national administrative capacity. Yet much international assistance is being channeled through agencies outside of government, with less than 25 percent of funds committed to government-managed programs. This pattern is related to the established operational capacity of UN agencies and NGOs coupled with donor reluctance to channel resources through government until it has demonstrated capacity to manage funds and oversee program implementation on a large scale. Ensuring success of the Government's initial set of investment programs, and aggressively communicating these successes to stakeholders, is thus a priority. IDA has been providing financial support to close to 100 percent of the current generation of government-managed projects under implementation, and the ADB has recently approved a program loan of $\$ 150 \mathrm{~m}$. The European Commission is also channeling funds through Government, and increasingly donors are responding to the Government's request to use their system.

37. While it is encouraging that the basic structures of government continue to function around the country, limited capacity in government has been a major constraint to progress of reconstruction, with ordinarily routine tasks becoming major stumbling blocks. Recognizing its serious capacity constraints, Government has been following a two-pronged strategy of bringing in international capacity on an urgent basis to handle critical functions while building up domestic capacity in these and other areas. Capacity building is intimately related to civil service reform, as the weaknesses in the civil service described earlier militate against building capacity in government on a sustainable basis. A key challenge will be to build capacity in government for assessment and decision making on reconstruction programs and policy reforms, contracting of implementing agencies, financial management, and overseeing the implementation of the reconstruction process.

\section{E. Aid Coordination and the Assistance Community}

38. The Interim Government, and subsequently the Transitional Government, have striven to exert leadership over the initially highly fragmented and ad hoc reconstruction process. In addition to the establishment of the AACA, which provides a focal point for guiding and coordinating international assistance, a key preliminary activity to bring cohesiveness and 
leadership to the reconstruction process was the development and promulgation of the National Development Framework (NDF) outlining the priorities and directions for the country's reconstruction and development. The draft NDF, presented to the international assistance community in April 2002, outlines a national strategy based on three pillars: humanitarian assistance and human social capital; physical reconstruction and natural resources; and private sector development (see Box 6, page 18). The NDF (described more fully in Section IV) also includes national priorities and policy directions and served as the basis for the subsequent National Development Budget presented to the international community in October 2002.

39. The NDF is grounded in a number of principles including an emphasis on the need for the development agenda to be an Afghan one - owned and directed domestically. It also recognizes the predominant role of the private sector in the country's development and stresses that for sustainability, donor activities must conform to broader national programs.

40. Policy coherence across the government and the broader reconstruction programs, particularly with respect to private sector-led development, gender mainstreaming, transparency and accountability, will remain significant challenges moving forward. These issues have been highlighted in government plans (such as the National Development Framework) and are being addressed, to some extent, through the formation of cross-cutting consultative groups which will provide input to, and be informed by, the groups working on the twelve National Development Programs.

41. In April 2002 the Interim Government produced a recurrent budget for Afghan fiscal year 1381 (March 2002-March 2003). The subsequent process to develop the National Development Budget (NDB) involved further consolidation of efforts between ministries to develop and focus on national priorities. The national budget is regarded by the Government as the central instrument of policy and resource allocation. The presentation of the NDB at the donor Implementation Group Meeting in October 2002 demonstrated that government leadership of the reconstruction effort is a reality. Active participation of cabinet ministers in the meeting clearly showed the progress that has been made in producing a coherent strategy owned by government ministries and agencies.

42. The NDB builds on the National Development Framework to outline a series of detailed programs, and specific projects within these programs, that form the core of the reconstruction effort. The NDB is intended to serve as a precursor to a more complete development budget being worked on, which will be presented at the first Afghanistan Development Forum meeting in March 2003. In addition to endorsing the twelve national development programs outlined in the NDF, the NDB also provides details of six high-priority programs for support by the international community.

43. Development of the national reconstruction strategy and government budget demonstrate the progress achieved by the Government to focus efforts and lead the development process, while also building cohesion within and among different ministries. Consultations with the international aid community, and continued efforts to align donor-funded programs with nationally prioritized programs, are proceeding well.

44. Following the post-September $11^{\text {th }} 2001$ period, multiple aid coordination processes emerged which, together with the multiplicity of donors and reporting requirements, constituted a heavy burden on an already stretched government. Significant implementation capacity exists in the NGO community and, to some extent, UN agencies, due to their extensive 
experience in Afghanistan. However, in the past this capacity was not linked to national leadership and priorities.

45. More recently, the Government has made progress in streamlining aid coordination with the functions of the donor-led Afghanistan Support Group (ASG) folded into the newly established government-led Consultative Group (CG) process (Annex 5). Implementation Group (IG) meetings have been the key linchpin of aid coordination, with two full meetings of the IG successfully held in Kabul in April and October 2002. The CG process is coordinating key government agencies and donor organizations within the National Development Framework and the full spectrum of national reconstruction programs (Annex 6).

46. However, the Government has been less successful in communicating its vision and accomplishments to the Afghan public. In order to consolidate the transition to a peaceful society and demonstrate the effectiveness of the newly established governing structure, it is essential that the Afghan public feel themselves to be part of the process and recognize the role of government in this process. Improved outreach to Afghan communities through a more effective public communications strategy, with a strong emphasis placed on implementation, is a priority if the Afghan public are to be brought along and fully recognize government leadership and accountability in the reconstruction process.

\section{IMPLEMENTATION OF THE BANK'S TRANSITIONAL SUPPORT STRATEGY}

47. The Bank's approach, outlined in the first TSS, was to build on sectoral assessments and strategies, such as those developed with funding from the Post Conflict Fund (PCF) (Annex 7 and Box 2), and those carried out by partner institutions, to identify urgent priorities and "lowhanging fruit" while also responding to, and helping build, the Government's reconstruction strategy and its overall leadership of the reconstruction process and aid coordination. This is done by working in close partnership with multilateral and bilateral agencies.

\section{Box 2 - Post Conflict Fund (PCF) \\ - the basis for a rapid response}

Prior to Bank re-engagement, analytical and consultative work carried out with PCF financing (see Annex 7) paved the way for rapid implementation of a short-term strategy once the Bank recommenced work in Afghanistan and provided much needed skills training for returnees. Subsequent to re-engagement PCF funding has been an important element in our ability to rapidly mobilize and deliver on strategic priorities:

- $\quad \$ 1.34 \mathrm{~m}$ in funding for the Priority Sectors Support Program produced much needed, and immediately relevant analytical work which underpinned future investments of the Bank, government and other aid agencies.

- $\$ 0.75 \mathrm{~m}$ provided funds to launch the Community Empowerment project - a vital bridging mechanism before IDA funds could flow.

48. The sequencing of Bank outputs and the ability to access PCF resources for urgent needs, until IDA Post-Conflict Grants became available, allowed a rapid response and has proved an effective approach. Trust Funds have complemented this approach. In addition to the ARTF, described below, the Japan Social Development Fund (JSDF), which established a dedicated window of $\$ 50 \mathrm{~m}$ for Afghanistan, has funded a number of complementary activities including support for initial phases of the National Solidarity Program and for improvement of the delivery 
of basic health services such as immunization, maternal care, and family planning in under-served areas. In addition, the NGO Support Fund enabled the Bank to get resources out to communities through NGOs relatively quickly. Additional grant funded activities are currently under consideration.

\section{A. IDA Post-Conflict Grants}

49. Following rapid approval of a total of $\$ 100$ million in IDA Post-Conflict grants for four projects (the first project approved only ten weeks after the Bank resumed work in Afghanistan, and the remainder in June 2002), implementation initially proceeded slower than expected, but with considerable variation across projects and sectors (Annex 3). In the latter part of 2002 progress on implementation has picked up considerably, with results on the ground now becoming more visible (Box 3).

\section{Box 3 - IDA funded projects - visible results are emerging}

\section{Emergency Public Administration (\$10m)}

- This project is the cornerstone of the Government's commitment to transparency and accountability, and important progress has been made. The Ministry of Finance is now able to generate accurate monthly expenditure reports, and has a computerized check issuance process both key steps on the way to developing a comprehensive revenue and expenditure management system.

- The procurement agent is actively processing contracts and providing capacity building to ministry staff.

Emergency Infrastructure $(\$ 33 \mathrm{~m})$

- NW Kabul power station has been recommissioned, almost doubling the available power supply in Kabul.

- Solid waste collection in Kabul is well underway and intensive public works are being conducted in the five largest municipalities.

Emergency Public Works and Community Empowerment (\$42m)

- Labor intensive public works are being implemented through NGOs under the Ministry of Rehabilitation and Rural Development in 8 provinces out of 16 planned, and the Ministry of Public Works has started surveys or commissioned work in 15 provinces. These efforts are expected to create more than 2.5 million person-days of paid labor over the next six months.

- The community empowerment project is forming the basis of design for the National Solidarity Program providing block grants to communities. A pilot is active in 16 communities in 7 provinces. Once scaled up the program aims to reach 10,000 communities throughout the country (between 2003 and 2005).

- Emergency repairs are underway on the Salang Tunnel - the main thoroughfare between the provinces of North Afghanistan and Kabul and the rest of the country south of the Hindu Kush.

Emergency Education ( $\$ 15 \mathrm{~m}$ )

- Student facilities in Kabul University-from chairs and desks to building renovation-are being improved. Future funding will encourage attention to increased female enrollment in the university.

- Government intranet now connects seven of the most strategic government agencies, and also provides internet and email connection.

- The Distance Learning Center is operational and a first event was successfully delivered on Infrastructure Finance, with more events being planned. 


\section{B. The Afghanistan Reconstruction Trust Fund (ARTF)}

50. The ARTF has rapidly become one of the main instruments for financing Afghanistan's recurrent budget (Box 4). Administered by the World Bank, and learning from experience with similar mechanisms in other post-conflict situations, the ARTF, established in April 2002, is a coordinated financing mechanism that provides support to the Afghan Government. Support focuses on three main areas of expenditure: recurrent costs of government such as the salaries of civil servants, including health workers and teachers; priority investments; and financing the return of expatriate Afghan professionals.

51. The key principle guiding ARTF financing is that the development program is country-led; thus it responds to country requirements as articulated by the Government. The ARTF is governed by a Management Committee, consisting of representatives of the $\mathrm{ADB}$, Islamic Development Bank, UNDP and World Bank, with day-to-day administration of the fund performed by the World Bank. A Monitoring Agent has been appointed by the World Bank to ensure proper fiduciary management. A Donor Committee supervises the management and administration of ARTF and provides policy guidance.

52. The ARTF has grown rapidly with pledges to date totaling over $\$ 200 m$ - while far exceeding expectations, still short of Afghanistan's needs. Of these pledges, paid in contributions from twenty-one donors totaled over $\$ 150 \mathrm{~m}$ as of the end of January 2003 (Annex 8). Disbursements have picked up in recent months with cumulative disbursements as of end of January 2003 reaching over $\$ 72 \mathrm{~m}$ - about 50 percent of total paid-in contributions.

53. Initial disbursements under the ARTF focused on supporting the first component of the fund-recurrent expenditures-and assisting the Government to meet its budget gap. Late 2002 saw the first approvals under the second component for priority investment and reconstruction projects. To date four projects have been approved for financing, totaling $\$ 42 \mathrm{~m}$. There have been delays in making effective the third component, which will finance return of expatriate Afghan professionals. Confirmation of the lead government agency to manage this component and some decisions on operational aspects such as procedures for identifying vacancies, transparent selection processes, and remuneration levels will allow it to proceed.

\section{Non-Financial Support}

54. The Bank has focused analytical and advisory services on providing quick, practical, concrete technical inputs and advice on specific policy, institutional design and reform issues. Indepth technical work has been conducted in response to Government requests in key sectors such 
as public administration, health, the financial sector, private sector development and infrastructure.

55. A variety of vehicles have contributed to this work, including Post-Conflict Fund grants, Technical Assistance components of IDA Grants, and partner financing of work. Results have been good particularly in the areas of public administration, private sector development and health, with strong positive feedback from the Government. In other areas results have been less satisfactory, with the Government raising concerns about reports that were not timely or in its opinion did not take into account the specific context of Afghanistan. A Gender Assessment was selected as the first flagship AAA task, but work was delayed by staffing constraints (see page 22).

\section{Arrears Clearance and Debt Sustainability}

56. Clearance of arrears to the Asian Development Bank, IDA, and IMF has been completed largely through grant contributions from Italy, Japan, Norway, Sweden, and the United Kingdom. This allows IDA to resume a normal financial relationship with Afghanistan.

57. Some concerns have been expressed about Afghanistan borrowing for reconstruction due to issues of debt sustainability. Because of weak base-year data and uncertainties about Afghanistan's growth prospects, any debt sustainability analysis will need to be continually monitored and updated as better information becomes available. IDA will work closely with the Government authorities and with the IMF in this regard.

58. It is clear, however, that the very large amounts of external assistance required to support the reconstruction of Afghanistan will need to be provided primarily on a grant basis targeted at key projects and structural reforms. Nonetheless, a preliminary baseline analysis shows that even at relatively high draws of concessional financing, debt sustainability ratios would be acceptable, ${ }^{6}$ provided that Afghanistan is not required to service its existing bilateral debt. Assuming moderate economic growth and rescheduling of bilateral debt, by 2008 the Net Present Value (NPV) of the debt stock to exports falls below 150 percent and the NPV of debt to revenues falls below 250 percent, both with sustained downward trajectories throughout the projection period. With outright forgiveness of existing bilateral debt, debt service to exports would remain below five percent during the entire projection period, and debt service to revenues below five percent for most of the period. ${ }^{7}$ This preliminary analysis, which will be refined as better data become available, highlights the importance of forgiveness of bilateral debts for the sustainability of Afghanistan's current plans for concessional borrowing from International Financial Institutions (IFIs).

\section{E. Assessment, Issues, and Constraints}

59. The first TSS highlighted six key outcomes for Afghanistan's reconstruction program that should be achieved during the nine-month period covered by that document, representing the

${ }^{6}$ Concessional borrowing (at IDA terms or the equivalent) in the amount of $\$ 300$ million per annum for ten years and $\$ 250$ million per annum thereafter, which-given Afghanistan's access to IDA grants for post-conflict countries-is in line with the pledges made for concessional lending in Tokyo.

post-conflict countries--is in line with the plecing paper with details on the specific assumptions, alternate assumptions and detailed tables of ratios will be prepared within the next several months, after further consultation with the authorities on baseline figures. 
country's own achievements, some of which were supported by the World Bank. As detailed in Box 5, many of these outcomes have been fully or largely achieved, while others have been at least partially achieved. Overall, progress has been significant and in many respects better than reasonably could have been expected last March.

\section{Box 5 - Progress Toward Outcomes of the first TSS}

TSS Outcome: The Afghan government fully in control of the reconstruction and aid process with sound financial management, procurement and other accountability mechanisms in place to facilitate the effective flow of funds.

Result: Largely achieved as Government has moved forward boldly and proactively to take leadership over the reconstruction process and has created a government-led Consultative Group mechanism. Capacity to handle government procurement, financial management and auditing is now in place and functioning well. There are still a few donors who operate to a large extent outside the Government's leadership and reconstruction/budget framework, but it is hoped that the situation in that regard will continue to improve.

TSS Outcome: The Afghan Interim Administration's (AIA's) priorities as reflected in the budget, adequately funded and essential government services reactivated.

Result: Largely achieved on the budget and funding side, slower progress in reactivating essential government services.

TSS Outcome: Increased employment and school enrolment (including women and girls), and improvements in basic infrastructure and facilities as a result of early recovery activities.

Result: Partially achieved. Sharp increase in school enrolments especially for girls, which is a tremendous achievement although quality and sustainability of the enrolment increase are now critical. Significant additional employment has been generated through public works programs, although still grossly insufficient. Improvements in infrastructure and facilities have not been as great as expected, and high unemployment remains a very serious problem.

TSS Outcome: Growth in agriculture, small and medium businesses, small scale construction and repair work underway and private sector regeneration in a range of areas.

Result: Partially achieved. There has been a considerable recovery of agriculture, with food grain production estimated to have increased by more than 80 percent in 2002 , primarily due to better weather. There has been some recovery of other sectors, especially construction, but this has been concentrated in Kabul and a few other places. Security remains a serious constraint to economic recovery in most parts of the country.

TSS Outcome: Donors organized around a comprehensive national framework for development and engaged in real coordination, led by Afghan authorities.

Result: Largely achieved in terms of expressed agreement, but scope for further progress in implementing the vision. The government-led CG process is underway, and it is hoped that this will be a vehicle for full-fledged donor coordination at the operational level.

TSS Outcome: Enhanced knowledge by the Bank and the international community of key sectoral and institutional issues important for Afghanistan's longer term development; active dialogue with the authorities on macroeconomic, budget and various policy and institutional issues.

Result: Partially achieved. Joint sector missions have built up a certain degree of sector knowledge, and considerable work has been done on public administration and other institutional issues. There is an active dialogue with the Government on some sectors, less active on others. However, there is a need to fill in gaps in dialogue and institutional knowledge (in part through the CG process), and progress in generating socio-economic data and economic statistics for Afghanistan has been limited. 
60. At the time of re-engagement, and while recognizing that Afghanistan is in many respects quite different from other post-conflict states, the Bank was also mindful of the lessons from international experience and strived to incorporate these into early actions including addressing capacity constraints and strategic sequencing of interventions. An assessment of the extent to which these approaches worked, and where further attention could have speeded up implementation, provides useful lessons both for continued engagement in Afghanistan as well as more broadly in the Bank's post-conflict work.

- Early Bank engagement can yield important dividends. Rapid implementation of the Emergency Public Administration Project meant that Government was able to bring in international capacity in the critical areas of procurement, financial management and audit. The financial management agent in particular has been very successful in introducing computerized treasury accounts and payments, and in training Afghans to carry out these functions effectively. The rapid preparation of three subsequent projects carried risks, as outlined in the first TSS, but nevertheless they have yielded important dividends and put the Bank in a better position to now expand assistance.

- Government leadership is essential but capacity is needed to exercise leadership. In order to be able to exercise leadership effectively, the government requires adequate capacity in core functions. This does not mean building up large and topheavy implementation or service delivery functions but building capacity for policy analysis, strategic decision-making, budgeting, financial management, and overseeing implementation. The limited pool of qualified professionals both within and outside government is a serious constraint. Donor-funded technical assistance in all key ministries is gradually increasing ministries' program management capacity.

- The Government's early decision to retain the services of a procurement firm to perform all major procurement tasks of the government, while building capacity of sector ministries, has proven to be effective. Government procurement systems have not been used for many years and there is also little tradition of outsourcing. Moreover, in a situation initially characterized by factional and ethnic divides, also reflected in ministry structures and leadership, procurement by individual line ministries would have run the risk of falling short of international standards. As line ministries build capacity and strengthen procedures, the need for centralized procurement is anticipated to decline. While a successful approach, the level of services initially contracted was insufficient causing a constraint to implementation. Corrective action has now been taken which should create sufficient additional capacity to ensure speedier implementation of programs.

- Security risks hamper implementation and private sector competition. A key constraint has been the relatively limited supply of private sector bidders responding to government tenders. Perceived security risks led several firms to withdraw their offers, even after being selected through competitive bidding processes. There is evidence that the situation is gradually improving as foreign firms begin to work inside the country and set examples for additional firms to enter the market. Yet this highlights the critical importance of improved security and the possible adverse consequences of negative perceptions of the security situation.

- In aid coordination, persistence pays off. The World Bank from the earliest stages was a strong advocate of several key general principles in aid coordination; government leadership; government budget as central instrument of policy and resource allocation; and coordinated external financing of reconstruction. Reservations were voiced initially from many members of the assistance community, and the Government (which also subscribed to these principles from the beginning) 
faced an uphill battle in convincing some donors to accept them. Nevertheless, continuing advocacy in support of the Government's position by the World Bank, supplementing the Government's own efforts in this regard, paid off - with these principles now embodied in the Government-led aid coordination process.

- The lack of a functioning payments system for international and domestic transfers of funds has been an important obstacle to the timely and effective delivery of reconstruction assistance. Early action to improve the payments system would have speeded up implementation of projects.

- There is a clear need for "bankable" project proposals and feasibility studies to encourage donors to fund development activities through the government budget.

- Timeliness and relevance in technical support and policy advice are essential. Afghanistan has been on a fast track and the Government wants to move ahead quickly with reconstruction, institutional development and policy reforms. Hence there is a premium on timely, relevant, country context-specific technical work. Large formal reports have not been very well received, particularly if they have a long gestation period.

- Bank presence on the ground is critical. The Bank initially established a strong presence through visiting missions, and the Kabul Office became functional in May 2002 with a core of administrative staff and some international staff staying on extended missions. However, there were significant delays in staffing up the office due to difficulties in attracting international staff, and in finding fully qualified national staff in a tight labor market in Kabul. The office has now become fully staffed on the international side, and progress is being made in recruiting national operational staff.

- Key policy issues cannot be neglected even in the early stages, and adequate attention needs to be paid to analytical work. Although early efforts, such as the preliminary needs assessment and joint sector missions, had a focus on "emergency" reconstruction needs and "quick wins", it rapidly became evident that key institutional and policy issues are at the forefront and should not be entirely preempted by the need for quick assistance.

- Arrears clearance became a bottleneck to Bank financial assistance after the first round of IDA Post-Conflict grants. Clearance of arrears to IDA was a prerequisite for further assistance under normal IDA-13 arrangements. Mobilizing donor support for arrears clearance was successful, but took a number of months as donor interest in contributing was initially limited, resulting in the delay of some IDA operations. Earlier focus on the arrears clearance issue would have paved the way for more rapid delivery of regular IDA assistance after the first set of grants.

- The considerable Bank staff time needed to work directly with Government and assist in implementation cannot be overlooked. This has implications for the Bank's administrative budget, particularly during the initial period when there must be greater reliance on international staff as opposed to national operational staff while the latter are being recruited and trained/oriented.

- NGO implementation capacity is valuable but becoming constrained. NGOs operating in Afghanistan for several decades represented, until recently, almost the only option for program delivery inside the country. However, utilization of their capacity is approaching saturation. This is proving to be a bottleneck and highlights the need to put in place mechanisms for the government to mobilize alternative institutions for service provision, including the private sector and communities themselves. 


\section{THE GOVERNMENT'S RECONSTRUCTION STRATEGY}

61. The Government has made progress in developing a reconstruction strategy", which recognizes the critical importance of state building to ensure the success of reconstruction and development efforts. An effective, functioning state is fundamental for development efforts to take hold. The role of the state as regulator and facilitator is crucial for well-functioning markets and a flourishing private sector, to ensure the efficient provision of infrastructure, promote human development and improve social indicators. Key components to support state building are capacity building and public administration reforms.

62. The Government has emphasized the need to address the sources and root causes of Afghanistan's serious humanitarian problems, not just the symptoms, while recognizing the need for continuing humanitarian assistance in the short run. Government argues that Afghanistan's dependence on humanitarian assistance should be reduced over time and eventually phased out, with an increasing proportion of international assistance going to reconstruction. The shift from a humanitarian/consumption to a reconstruction/investment focus is consistent with several related transitions that the government is advocating, including:

- From in-kind commodity aid to cash assistance (e.g. from food-for-work to cash-forwork)

- From assistance directly to implementing agencies (outside the Government budget) to aid that passes through government budget channels

- From assistance that is "sole-sourced" to specific implementing agencies to transparent, competitive contracting.

63. A shift from a humanitarian to a longer-term reconstruction and development focus as described in the National Development Framework (Box 6) would also enhance government leadership and open the way for better alignment of international assistance with the government's reconstruetion strategy and budget.

64. Government has clearly asserted that the budget will form the central planning tool. As noted earlier, the Government is improving processes for compiling both the recurrent and development budget. Further improvements in budget execution, building on the progress already made, also are needed.

65. Government has identified good governance as a priority, recognizing the pivotal role of governance in establishing a transparent and accountable government and in attracting private sector development. Promoting good governance serves as a cross-cutting theme in the Government's development strategy. Support from the IDA funded Emergency Public Administration Project provided the first steps in addressing certain aspects of this strategy.

\footnotetext{
${ }^{8}$ Information on the Government strategy is derived from the National Development Framework and other Government documents. See http://www.afghanistangov.com
} 
Developed and presented in April 2002 by the Afghanistan Interim Administration, the draft National Development Framework provides the basis for the Government's reconstruction planning, and prioritizes programs for support.

The NDF is based on three pillars:

- Pillar One - Humanitarian Assistance and Human and Social Capital - recognizing the continuing humanitarian crisis and the need to address the pressing needs of the vulnerable, including refugees, programs will focus on creating the conditions for people to live productive and secure lives through community development and developing social capital.

- Pillar Two - Physical Reconstruction and Natural Resources - supporting reconstruction activities to expand physical infrastructure and provide employment opportunities as well as laying the basis for a private sector-led strategy of growth. Programs include urban development and attention to municipal development, roads, transport, water and sanitation.

- Pillar Three - Private Sector Development - developing a competitive export-oriented economy, to provide the engine of growth and instrument of social inclusion through the creation of opportunities.

Under these three pillars, the Government has put forward Twelve National Programs (Annex 9) being prepared through a consultative process led by key ministries and involving relevant agencies and donors.

Pillar One

- Refugee Return

- Education

- Health and Nutrition

- Livelihoods and Social Protection

- Cultural Heritage, Media and Sports
Pillar Two

- Transport

- Urban Management

- Energy, Mining and Telecoms

- Natural Resource Management
Pillar Three

- Trade and Private Investment

- Public Administration

- Security and Rule of Law

In addition three important cross-cutting themes have been identified to be addressed within each program:

- Governance, financial management and administrative reform - Efforts will include creating an enabling environment for civil society development, ensuring equitable development by addressing provincial needs and those of urban and rural areas, and developing systems for financial management and public administration that are transparent and efficient.

- Human Rights, Security and Rule of Law - without security it is acknowledged that development efforts will have little chance of taking hold. A priority will be the development of a national police force and army, re-absorption of combatants including through vocational training, and reviving the judicial system. This cross-cutting issue also recognizes the broader meaning of security in removing barriers to inclusion and providing equal opportunity.

- Gender - this will have a two pronged approach - first to restore rights to women and girls that were removed under the Taliban, particularly with regard to income earning opportunities, and second to undertake a process of assessment across sectors- political, economic and social - to ascertain how to promote the inclusion of women.

66. In its NDF and Budget the Government has taken a programmatic approach to policymaking and resource allocation. Underlying the framework and programs delineated by the Government is a strong belief that investment projects, unless anchored in coherent programs, will not be sustainable. This approach drives the implementation strategy which, it is hoped, will help align donor support with national priorities, avoid duplication and leverage the benefits of individual project activities. Recognizing capacity limitations and to enhance the implementation 
of this strategy, the Government has established a Feasibility Studies Facility to assist line ministries in the design of programs and projects.

67. The Government has committed to developing a series of self-imposed benchmarks to accompany the integrated development and operating budget, which will be promulgated in March 2003. The benchmarks, which will outline the timetable for the Government's reform agenda, are being developed by the Government itself to ensure full national ownership. Donor and NGO members of the twelve newly-formed Consultative Groups are working with Government to assist in the process of defining benchmarks and will, in the future, focus on monitoring performance against benchmarks in close collaboration with Government partners.

68. Progress has been made toward donor alignment through the Consultative Group Process (Annexes 5 and 6). Donors are now coming together around the NDF and engaging in regular communication with Government counterparts to align their current activities and planned projects within the overall budget process. Strong donor interest in certain areas including education, health and transport, along with significantly less interest in other strategically important areas, coupled with the Bank's ability to provide valuable support in underserved areas, has provided the basis for the Bank's proposed strategic focus over the next two years.

\section{THE WORLd BANK'S TRANSITIONAL SUPPORT STRATEGY}

\section{A Client-Driven, CDF Approach}

69. The reconstruction strategy developed by the Government forms the framework within which this TSS has been prepared. Developed in consultation with the Government and other stakeholders, it reflects Government priorities for Bank financial and non-financial assistance as well as the areas of comparative advantage of the Bank in line with a Comprehensive Development Framework (CDF) approach. This strategy covers a period of 18 months to 2 years, until Afghanistan's new Constitution is promulgated and a stable, representative government under the new constitutional arrangements is established, in line with the process mandated by the Bonn Agreement. At that time it is anticipated that Government will begin work on a PRSP, and work on a Country Assistance Strategy (CAS) will be initiated.

70. In view of the continuing uncertainties and risks associated with Afghanistan, this TSS like its predecessor will be treated as a flexible guide, to be refined and adjusted as developments warrant. The Board of Executive Directors will be regularly briefed on progress with implementation of the Bank's strategy.

\section{B. Key Objectives}

71. The key objectives of this strategy are to support the continued development of a wellfunctioning, state that is accountable to its citizenry and able to ensure the delivery of services in an equitable, efficient and effective manner. Consolidating the gains made from peace and addressing issues of state building will lay the foundations for longer-term growth and poverty reduction. Extending the reach of public services and jurisdiction into the provinces, as well as improving financial management and administrative effectiveness, will be key. Poverty reduction remains a crucial longer-term goal for the Bank, particularly recognizing that Afghanistan is not only one of the poorest countries in the world in terms of per-capita income (most probably the 
poorest country in Asia), but it also has among the worst social indicators in the world and is far behind in terms of the internationally agreed Millennium Development Goals (MDGs) (Annex 4).

72. These broad goals translate into a number of more specific objectives in terms of shorterterm outcomes for Afghanistan during the period covered by this strategy, which would set the stage for further progress.

- Enhancing government effectiveness: Particular focus is needed on policy formulation, decision-making, nationwide reach, regulation, supervision, and where appropriate implementation, and also in terms of budget preparation, budget execution, and domestic revenue mobilization.

- Strengthening communities: Communities, which form the linchpin of the Government's reconstruction strategy, need to be strengthened so as to be better able to identify and prioritize their needs and to develop and carry out coherent plans for local development.

- Enabling private sector dynamism: A conducive environment for the private sector - which will be the engine of Afghanistan's longer-term economic growth and poverty reduction - needs to be established, including appropriate market-oriented and pro-private sector policies, good governance, and adequate infrastructure.

- Generating incomes for the poor: Initially this would be accomplished through employment in labor-intensive public works activities, and over time shifting toward productive income-generating activities.

- Providing basic social services to the population: Given the very low levels and often poor quality of basic education and health services in Afghanistan, considerable progress can and should be made in expanding coverage, improving social indicators, and creating a foundation for further progress on a sustainable basis.

73. The Bank will help promote these outcomes, in line with Government reconstruction priorities and programs, with selectivity based on the configuration of the international assistance community as a whole and the Bank's areas of comparative advantage. A related goal of the TSS is to begin to make the transition in the Bank's approach to partnership with Afghanistan from a short-term, re-engagement, "emergency" orientation to a longer-term development effort, the foundation for which has been laid in the Bank's initial activities.

74. Strategic focus and selectivity in Bank assistance are essential to best help Afghanistan fulfill its national reconstruction and development agenda. This is very much in line with the principles of the CDF and responds to the Government's request that donors be selective and focus their assistance on a restricted number of the twelve NDF programs.

75. In defining the Bank's strategic focus and selecting areas to support, a number of issues have been considered, in particular:

- the Bank has greater comparative advantage to support Afghanistan's reconstruction in some sectors and areas of activity than in others;

- the coverage of different sectors and areas of activity by the rest of the international assistance community varies, with heavy donor interest in some sectors and limited or non-existent interest in others;

- given the large amount of donor funded technical assistance available to Afghanistan, Bank advisory services will focus on high-level strategic advice that complements the work of others or fills gaps in donor assistance, generally leaving detailed capacity or institution-building to bilateral donors; 
- the Bank's limited staff and administrative resources can be best employed by focusing on a few critical areas where the Bank has a comparative advantage; and

- the burden on Government will be reduced if the Bank and other assistance partners focus their activities rather than getting involved in a large number of sectors and areas.

76. Based on the above considerations and consultations with the Government, civil society, the private sector and other development partners (Annex 1), the Bank will focus on four broad areas:

- Improving Livelihoods: employment generation, community development, and the rural economy including water resources management; drug eradication, though a pressing issue, will not be directly targeted but the Bank remains mindful of this in its interventions. Similarly, the specific needs of returning refugees will not be treated as a separate area of focus but Bank interventions will take into account those areas most affected by refugee return.

- Fiscal Strategy, Institutions, Management: budget, role of Ministry of Finance, revenue and expenditure arrangements, central-local fiscal framework.

- Governance and Public Administration Reform: role of state, financial transparency, good governance of public administration, civil service reform.

- Enabling Private Sector Development: business climate, financial sector, infrastructure, regulation, trade, reducing bureaucratic 'red-tape' constraints.

77. The Bank's work program will be organized around and fully consistent with the above areas of focus, and the Bank will continue to work in close partnership with the Government, donors, and other assistance partners as well as through the Consultative Groups associated with these areas.

78. In line with the need for selectivity and focus and to prioritize limited resources, the Bank does not expect to develop any major new activities in other areas where it is significantly engaged at present-most notably transport, education, and health-beyond activities already at an advanced stage of preparation. While these sectors are crucial for Afghanistan's reconstruction and for achieving the desired outcomes mentioned earlier, they are sectors where there is strong interest on the part of other donors.

79. There are a number of significant cross-cutting issues which will be addressed both within ongoing and planned projects and through focused TA and analytical work. Issues of gender inequity, environmental and social problems and governance stand out as particularly important. 
80. Causes of gender inequity are complex everywhere, especially in Afghanistan - due to a combination of poverty, the effects of war, local customs, and various other cultural dimensions. Emancipation of women has been controversial in Afghanistan's history. Reforms initiated by King Amanullah in the 1920 s and in the communist revolution in the late $1970 \mathrm{~s}$ provoked a backlash from traditionalist elements in society. Traditional Afghan "cultural" institutions, which some see as the main source of the present Afghan problems, have on the other hand preserved the family and community structure surprisingly intact in spite of more than two decades of dislocation and war. The resulta considerable degree of social cohesion and ability to put communities back together-is a major asset for Afghanistan. This illustrates both the strategic importance attached to the gender issue and its complexity in the Afghan context. Looking forward, the Bank will continue to follow a two-pronged approach on gender issues, through mainstreaming equity considerations in our work and also conducting a longerterm gender assessment.

81. The Bank will continue its low-

Box 7 - Gender Assessment

The gender dimensions of poverty in Afghanistan are shocking:

- Maternal mortality, at 1,700 (per 100,000

live births) is the highest in the world

- The lifetime risk of maternal mortality is 1 in 15

- Under-5 mortality rates are 279 (per 1000 live births)

- Neonatal mortality rates (the first 4 weeks of life) are 121 (per 1000 live births).

Recognizing that approaches to addressing gender issues must be developed and owned within Afghanistan and cannot be imposed from outside, the Bank will play a role in conducting analysis to stimulate debate and increase awareness of key issues.

Working with partner institutions, the Bank will prepare an Afghanistan Gender Assessment, which will take as its point of entry the maternal mortality and under-5 mortality rates, among the worst in the world and a threat to the future of the country. Against this background, the gender issue will be addressed from a wider poverty perspective, exploring linkages among health, education, poverty and gender discrimination.

profile mainstreaming approach, as is demonstrated for example in the National Solidarity Program - which attempts to engage women in decision-making through the employment of female field workers to mobilize women's groups. Yet it is recognized that regional differences within the country are likely to produce varying results. In labor-intensive works programs, activities for women will be included, keeping in mind social and cultural sensitivities.

82. The enormous environmental and social problems existing in Afghanistan will take many years to address. The Bank will continue to follow the approach set out in the first TSS to ensure that social and environmental due diligence requirements of the Bank are interpreted in a pragmatic way that is adapted to both the urgency of the recovery effort and the needs on the ground. Flexibility is required, especially concerning partnership instruments such as the ARTF, where management is shared with other multilateral organizations and where there are high government and donor expectations of quick results on the ground. To address some of the more pressing social issues-including reintegration of ex-combatants and returning refugees-the Bank is not targeting specific groups for assistance but will incorporate the needs of such groups in projects, along with others whose needs may be even greater. For example, labor-intensive programs and community driven development initiatives will be mindful of such groups while also addressing the needs of the broader society. With respect to environmental issues the Bank will conduct analytical work to begin to address some of the most pressing issues in the area of water resources management.

83. Issues of governance cover a broad spectrum including developing an effective, transparent and accountable public administration. The Bank is supporting improved governance 
under the Public Administration Project through activities that assist the Government divest trading activities and utilities and create independent regulator arrangements, as well as through improved financial management, procurement and audit processes which guide implementation of other IDA-funded investments. Analytical work will address this cross-cutting theme in a number of areas including civil service reform and local-provincial administration. However, governance issues are not restricted to the national level and the state apparatus. For national, provincial and district governments to be responsive, communities need to develop mechanisms to identify and prioritize their demands. IDA supported community driven development initiatives (which form part of the National Solidarity Program) play an important role in laying the groundwork and assisting communities to support improved governance at all levels.

\section{Priorities for IDA Assistance and Analytical Support}

84. The program of Bank assistance will maintain a considerable degree of flexibility in order to effectively support Afghanistan's reconstruction in the evolving situation. Planned and anticipated Bank financial assistance and analytical and advisory activities (AAA) within each area of strategic focus are briefly summarized below. Annex 10 outlines the tentative IDA funded program through FY04. It is anticipated that IDA financial support will be used to finance critical sectors or activities where other donors are relatively inactive, where there is a gap in finance for infrastructure critical to the rehabilitation of the economy, to demonstrate innovative approaches for the delivery of services, to finance short-term costs of reform, and for financing the Government's recurrent budget as needed, based on a strong, coherent reform program. Within overall IDA assistance to Afghanistan, IDA grants provided under the provisions of the IDA-13 replenishment will be spent on activities with the most direct impact on poverty reduction, such as basic public health services, labor-intensive public works and community development, as well as critical TA.

85. Improving Livelihoods: Support will focus on four main areas: community development and labor-intensive public works, water resources management and microfinance. The politicized nature of anti-narcotics programs, and their link with security, prevent the Bank from directly engaging in these activities. Yet the Bank is aware of the problems and will address them through the broader livelihoods program.

- Community-Driven Development and Labor-Intensive Public Works: The IDAfinanced project currently under implementation has helped launch two of the Government's national priority sub-programs, one of which funds block grants and participatory planning for community-driven development, and the second laborintensive public works. Additional IDA funding for FY03 and FY04 is likely to be provided depending on a review of early results. Expanded IDA support would help the Government achieve tangible results and develop local infrastructure, as well as contribute to improved local governance. It is also hoped, depending on early results, that other donors will come in with additional financial support for these important national programs, which share the same institutional arrangements that strengthen government leadership and accountability of non-government deliverers of public services.

- Water Resources Management: IDA support has been requested for water resources management. Rehabilitating existing irrigation schemes and converting arid land into cultivable areas through new investments are priorities for development of the rural economy. Joint sector reviews by the World Bank, ADB and FAO have identified the potential for a number of investments which the Bank will assess in more detail using a basin management approach. Potential IDA contributions will be considered in the light of this analysis. 
- Micro-Finance. The Bank is following a phased approach, with the first phase comprising a one-year pilot (with a proposal for partial funding having been approved by ARTF and a proposal for the remaining funding currently being considered by the JSDF) to provide financial and technical assistance to a small number of qualified NGOs to support on-lending activities and institution building. The second, expansion phase, for which IDA financing may be requested, anticipates the establishment of an autonomous, non-profit micro-finance support facility to wholesale funds and provide capacity-building support to micro-finance institutions throughout the country.

86. Fiscal Strategy, Institutions and Management: Continued assistance will be provided through the ARTF, described earlier, as well as through a possible Fiscal Rehabilitation project in FY04. Additionally, the Bank is facilitating an "Economic Management Strategy Discussion Series" at the request of the Government. This will comprise some issues and options notes setting out some of the major choices confronting policy makers and political leaders, and holding of informal workshops, facilitated by leading experts, to assist in exploring difficult reform alternatives. The three areas of focus will be: the lessons learned from other post-conflict settings with complex political coalitions concerning the roles and structures of major economic management ministries; the economic management implications of likely reforms to the architecture of the state (including executive/legislative relationships, constitutional position of the Central Bank, organic budget law, veto authorities of the Minister of Finance, etc.); and the management and implementation of reforms.

87. Governance and Public Administration Reform: Ongoing work is supported by a combination of AAA, the Public Administration Project, and a second Public Administration Project currently under discussion. These activities will continue to focus on addressing three key areas-financial management, procurement and audit-to build capacity for sound management of public funds and demonstrate accountability for foreign assistance. Other areas of focus include accounting and auditing separation, and the establishment of a public accounts committee or similar oversight body. Through the ARTF, the Bank is also engaged in more detailed dialogue on improving the payments system and the quality of overall monitoring. Additional efforts will be devoted to accelerating the execution of the budget, particularly in the provinces, ensuring the timely payment of salaries, improving the quality of budget preparation, supporting customs reform, and assisting the Government to address issues of civil service reform. It is also planned to intensify dialogue and AAA/TA to assist in reforms within selected ministries.

88. Enabling Private Sector Development: Bank support will address key issues to help create an enabling environment for private sector development, while also focusing on specific areas of transport (in the short term), power and energy, and telecommunications.

- Private Sector Development support is still under discussion but may include assistance for the legal framework including for customs and trade, supporting a suitable certifications body to facilitate exports to OECD, compiling a register of state assets and appointing a body to oversee the privatization process. A proposal (for $\$ 5 \mathrm{~m}$ submitted to JSDF) would provide support for a number of areas including improving the regulatory and legislative frameworks that support commercial and business activities; improving services, facilities, and functions of selected key institutions that support the private sector; and funding a youth development project to provide entrepreneurial, training to disadvantaged youth. The Government is currently pursuing membership in MIGA to take advantage of its political risk 
guarantees for foreign direct investment. MIGA is considering creating suitable risk mitigation products to facilitate foreign direct investment and the return of flight capital into Afghanistan. MIGA undertook its first mission to Afghanistan in January, and is currently finalizing a proposal to create a trust fund, which it will submit to interested donors. IFC's program in Afghanistan is focusing on the financial sector, including SMEs, microfinance and the establishment of a commercial bank, business hotels, and potentially telecoms. A number of activities are under preparation (Annex 11).

- Financial Sector assistance will focus on strengthening the institutional and operational capacity of the Afghanistan Central Bank. Another area of focus is the banking and non-banking sector's efficiency and effectiveness in financial resource mobilization and allocation. IDA support may be provided to develop the Central Bank's operational capacity and the financial sector's developmental and intermediation role and to support re-establishment of a commercial banking sector. Analytical and technical assistance will focus on developing a medium-term financial sector strategy in conjunction with the MOF and donor partners, and a draft Financial Sector Study with three main areas of coverage: central banking; commercial banking; and the informal financial sector (the hawalas). IFC has contributed to the development of this sector through investment in and support for establishing the First Micro Finance Bank of Afghanistan (FMBA).

- Telecommunications assistance is focused on helping the Government to implement its new telecommunications policy which supports the introduction of private-sector led competitive provision of infrastructure and services as the primary tool of sector investment and growth, and to support the rollout of communications services to meet public and private sector communications needs. Bank assistance will primarily be through AAA with support for investments and capacity building provided through special funds (ARTF and PPIAF).

- Power sector assistance will focus on completing rehabilitation investments that are underway (through the Emergency Infrastructure Reconstruction Project) and engaging in policy dialogue on the future strategy for the sector, immediate investment needs and updating the investment strategy, subsidy and tariff issues, and rural access to energy services. A follow-on energy project might also be requested for IDA funding.

- Water Supply and Sanitation assistance will focus on implementing rehabilitation investments (through the Emergency Infrastructure Reconstruction Project) and engaging in policy dialogue on sector strategy, including subsidy and tariff issues, coordinated with the work on the power sector, to promote a consistent approach to utility support and reform.

- Oil and Gas and Mining sectors support will be conducted through AAA by engaging in policy dialogue and providing TA to the Ministry of Mines and Industry, particularly for the establishment of a new petroleum policy and the new mining policy, as well as a legal, regulatory and tax framework that promotes private investment in the sector.

- Urban Infrastructure assistance, which is under discussion with the Government, will help introduce contemporary techniques of urban planning, initiate programs for community-based upgrading of informal urban neighborhoods, urban land use planning, and initiate modernization of the urban land management system.

- Trade is an important area of development potential, and based on a request from the Government, the Bank, building on earlier studies of the Afghanistan border states region, will be conducting a study of regional trade issues and prospects involving 
staff from different Bank central and regional units (including South Asia, Europe and Central Asia and the Middle East and North Africa).

89. Areas of Consolidation: As noted earlier there are three areas where the Bank is currently engaged but where we do not anticipate launching any major new work (other than projects already far advanced in preparation) during the period covered by this strategy, in line with the CDF approach agreed with Government, the transition from emergency activities to longer-term engagement, and based on comparative advantage. The situation will be reviewed in light of actual implementation experience, and further adjustments will be made when a full CAS is prepared. The three areas are:

- Health: the Bank plans to assist the Government to demonstrate provision of basic health services through performance-based contracts with non-government service providers at the district level. Once this system is proven operational it is anticipated that the system of government contracting and financing of NGO service providers will be supported by assistance from other donors. AAA work will include a health sector review and analysis, using results of a baseline household survey (to be financed jointly by the education and health projects), and a health facility census.

- Education: this is a priority sector for many donors and should be well funded if the pledges made in Tokyo in January 2002 materialize. Current Bank involvement was primarily an early response to the emergency needs of the under-funded higher education sector before the Government budget was financed and operational. The Bank will continue to support the Government through the Emergency Education project including important analytical work and the development of innovative approaches and financing mechanisms to address learning space issues and education for girls.

- Transport: the Bank was asked to quickly mobilize early technical support and financing for the critical northern highway from Kabul to Kunduz and the Tajikistan border, and for upgrading aviation safety at Kabul airport. The Emergency Transport Project will facilitate the country's economic and social recovery through improved physical access to goods, markets, and administrative and social services. Provided that strong bilateral and multilateral donor interest in financing the transport sector continues, the Government intends to use Bank resources for other sectors.

\section{Implementation of the Transitional Support Strategy}

90. In terms of implementation, the Bank's program will continue to help build Government capacity to oversee and regulate the reconstruction process, while maximizing engagement of the private sector, community groups and NGOs in the implementation of the reconstruction program. Over the period of this strategy, implementation of programs throughout the country is anticipated to increase substantially, including through the facilitation efforts of NGOs contracted by the Government under the National Solidarity Program. Additionally, the Bank will intensify dialogue and capacity-building efforts through TA and AAA. The Bank will continue to work in close partnership with the IMF, ADB, Islamic Development Bank, UN agencies and bilateral partners.

91. The Bank's country office in Kabul is now fully functioning although still in need of additional national operational staff. Given the circumstances in Afghanistan and the considerable interaction of staff with counterparts, staffing issues will need careful consideration and are likely to result in the Afghanistan program needing additional resources, compared to the 
size of the program, than other country programs. In addition to ensuring close coordination with Government counterparts, including policy dialog, and playing a substantive role in development planning through some of the local consultative groups involved in the CG process, the country office will also make efforts to improve outreach and communication. Current engagement includes regular interaction with local media, a public website, use of the Development Gateway, and an active series of programs using the GDLN center. Plans are being developed to engage more regularly with civil society and other development partners on topics of mutual interest.

92. As already noted the Government, with inputs from the international community, is engaged in a process to define nationally owned benchmarks to monitor progress on implementation of the reconstruction program. In addition to assisting the Government in defining benchmarks and monitoring progress, the Bank will align its own efforts with those of the Government and will encourage others to do the same. This will mitigate the risk of fragmentation of assistance and will enhance prospects for successful implementation as well as supporting the Government's efforts. An additional important monitoring effort will be the use of independent external monitors in some IDA funded projects.

93. Although specific benchmarks will be put forward by the Government in the near future, a number of illustrative benchmarks are shown below (Box 8) for the key outcomes at the national level, listed earlier.

\section{Box 8 Illustrative Benchmarks of Outcomes for Afghanistan}

Enhancing government effectiveness:

- Organizational improvements (e.g. streamlining number of ministries)

- Improvements in the skills level of the civil service

- Level of domestic revenue mobilized by the national government

- Separation of core government functions and employees from public enterprises

- Accurate and timely payment of government payrolls

- Level of non-salary O\&M expenditures, especially outside of Kabul

Strengthening communities:

- Number of communities successfully mobilized under NSP

- Number of communities receiving block grants under NSP

- Outcomes achieved by block grants

Enabling private sector dynamism:

- Size of quality infrastructure networks (e.g. roads, telecommunications, power, airports)

- Quality and functioning of enabling regulations for domestic and foreign investment

- Development of financial sector (regulatory framework, domestic and international payments system operational)

- Level/growth of exports

Generating incomes for the poor:

- Level of agricultural and livestock production

- Number of person-days of employment provided through public works programs (including number for women)

- Number of people reached by quality micro-credit programs

Providing basic social services to the population:

- Number of children in school, disaggregated by gender

- Number of children immunized

- Number of people with access to/reached by basic public health services

- Number of people with access to safe drinking water in urban and rural areas 
94. With respect to the World Bank program and the ARTF, the following are broad benchmarks for the duration of this strategy:

\section{Non-financial assistance:}

- Client Evaluation of World Bank policy advice and technical support positive, in terms of quality, relevance, and timeliness.

- Quality at Entry of AAA tasks judged to be at least fully satisfactory by World Bank Quality Assurance Group recognizing that Afghanistan is in the process of emergency recovery (based on random sampling).

- Completion of quality Gender Assessment and effective process for mainstreaming gender concerns in World Bank operations and activities.

- Effective technical support to good practice, country context sensitive regulatory frameworks and institutions for infrastructure and energy sectors.

Financial assistance:

- Quality at Entry of projects judged to be at least fully satisfactory by World Bank Quality Assurance Group, recognizing that Afghanistan is in the process of emergency recovery (based on random sampling).

- Commitment of IDA assistance in line with the World Bank's Tokyo pledge.

- Disbursement of IDA assistance in a timely manner. Disbursement ratios for IDA-13 projects of at least 25 percent per year.

- Results on the ground from IDA assistance, including overall progress in the sectors/programs supported and project-specific indicators.

\section{Benchmarks for ARTF}

- Effective management and reduction of fiduciary risk associated with ARTF-funded expenditures.

- Accuracy and timeliness of payroll documentation increases progressively over time.

- Non-wage recurrent expenditures growing, with monitoring of use and asset management plans where appropriate.

- Development component procedures smoothly functioning, with effective appraisal of proposals.

\section{Prospects, Risks and Mitigation Measures}

\section{A. Prospects for Economic and Social Recovery}

95. As was emphasized in the first TSS, prospects for economic and social recovery will continue to depend on both improvements in security and continued consolidation and enhancement of the Government's role and in particular the policy and program choices it makes, which will be key in determining the country's future development. The timely implementation of political benchmarks as set forth in the Bonn agreement bodes well for enhanced political stability in the country. Yet the continued sporadic fighting and lack of security in many areas demonstrate that peace is still fragile. Concerns over repercussions from instability in the broader region, including a possible conflict in Iraq, cannot be overlooked.

96. Initial signs of economic recovery and actions taken by the Government to date illustrate that significant gains can be made if peace and stability take hold. The high number of refugees who have returned during the first year, far exceeding expectations, further demonstrates public 
hope and support for continued peace. Government support can be heightened if more tangible results that impact on the daily lives of the Afghan people can be quickly brought about.

97. Despite current problems, Afghanistan's potential for economic recovery and longer-term development should not be underrated. The reconstruction program itself and private rebuilding will generate large demand for construction services and other related industries. The recovery of agricultural production in 2002 and the prospects for continuing agricultural growth in 2003 based on good winter precipitation provide a foundation for economic recovery. There is potential for growth of traditional and non-traditional exports, and for transit trade and other activities taking advantage of Afghanistan's location. Realization of this potential is, however, very much contingent on improved security and continuing progress toward political stability and enhancement of rule of law.

98. Prospects for Afghanistan's longer-term economic growth and poverty reduction will also depend in large part on sound policies, successful reforms and effective institutions, the foundation for which needs to be established during the period covered by this TSS. The Government has commendably taken a strong private sector-oriented approach to the economy and reconstruction, but on the other hand the legacy of statist, public sector-based development remains in the form of numerous public enterprises, public sector commodity procurement, and investment licensing. Thus a strong reform program is needed to deal with this public sector legacy and realize the Government's vision of private sector-led development.

\section{B. Risks Remain High and Need to be Managed}

99. While significant progress has been made in the past year, the most critical risks remain those identified in the first TSS-the possibility that the fragile peace process and political developments underway will become disrupted, whether due to internal instability or catalyzed by external events. The continued lack of security and sporadic fighting around the country remain significant causes for concern. Moreover, heightened tensions associated with a possible war in Iraq cannot be overlooked. The negative repercussions of such a war-which could see a deterioration in the security situation - could lead to at least a temporary setback in early gains and delay Afghanistan's recovery. There are also serious concerns about possible diversion of attention of countries currently supporting reconstruction. Even if such a negative scenario does not materialize, should the security situation not improve, the risk of further entrenchment of regional warlords, ethnic tensions, and inability of the political process to move forward would pose serious threats.

100. As in the first TSS, the Bank will continue to focus on high-impact activities, while also working with the Government to help strengthen its ability to manage the country's reconstruction efforts. Public works employment programs and community-driven development under the National Solidarity Program are two notable examples of Bank-supported activities that, if successful, will strengthen the outreach of the state and mitigate risks to the peace process and political normalization.

101. The Bank will continue to closely monitor the security situation and is prepared, should the situation deteriorate, to adjust modalities of working while continuing to provide support to Afghanistan's reconstruction.

102. Capacity constraints and lack of qualified government staff continue to pose risks to the implementation of reconstruction programs. Nevertheless, the Government is aware of this constraint and progress has been made already. There is evidence that, both through government 
and donor efforts and Bank programs, attention will continue to be paid to this crucial issue. Concerns regarding the Government's ability to manage the complex aid coordination process, cited as a risk in the first TSS, have been reduced considerably with progress being made in a government-led CG process, supported by the good will of international assistance partners.

103. The Government has maintained admirable fiscal and monetary discipline during the past year, including a no-overdraft policy for government expenditure and avoidance of inflationary money creation. However, as larger amounts of external assistance flow in and demands on the government grow, there is a risk that fiscal discipline will erode, possibly leading to macroeconomic problems as well as wasteful use of scarce public resources. The Bank, together with the IMF, will work closely with the Government to support its efforts to maintain fiscal and monetary discipline, including through technical assistance to improve the information base and strengthen the instruments of macroeconomic policy.

104. Another risk, which could impact on World Bank financial assistance to Afghanistan, would materialize if forgiveness of bilateral debts is less generous than hoped, reducing the debt-sustainability of planned/pledged concessional lending to Afghanistan by IFIs. This highlights the importance of forgiveness of Afghanistan's bilateral debts, which would enable Afghanistan to engage in substantial new concessional borrowing. If debt forgiveness does not fully materialize, the IFIs will need to review, and if necessary reduce, their plans for concessional lending to Afghanistan, keeping in mind the grant elements and components of different forms of assistance.

105. A reduction in donor interest in continuing to support Afghanistan's longer-term development efforts remains a risk. Despite repeated assurances from Afghanistan's international partners of their commitment to the country, concerns remain that events beyond Afghanistan could still have an impact in diminishing the focus on Afghanistan. The experience of other post-conflict countries shows that absorptive capacity for foreign assistance increases above normal levels three or four years after the end of the conflict-the time when donor assistance sometimes flags. Without continuing external support, the country runs the risk of having inadequate resources to sustain the reconstruction efforts underway, to further consolidate state functioning, and to reach out to Afghans around the country.

James D. Wolfensohn President

By Shengman Zhang

February 14, 2003

Washington, D.C. 
ANNEXES 


\section{Annex 1 \\ Consultations on the World Bank's Transitional Support Strategy}

1. A series of informal consultations on the TSS were held in Kabul in January 2003, to seek input and feedback from Government, donors, NGOs and the private sector (see below for a list of agencies consulted). The Bank received widespread support from stakeholders for the areas of strategic focus proposed in the TSS, in particular the attention to public administration and other efforts to assist government, such as in civil service reform. This note summarizes major areas of discussion, issues raised, and World Bank responses where applicable. Views and suggestions of stakeholders have been incorporated into the strategy to the extent feasible.

2. The very poor security situation in Afghanistan, the difficulties of implementing reconstruction programs, travel and developing businesses were stressed.

$>$ While outside the Bank's direct mandate, there is clear recognition of the fundamental importance of improvements in security and the fact that the fragile security environment in Afghanistan remains a key impediment to achievement of large scale reconstruction and rehabilitation throughout the country. The Bank will continue to raise this issue as a major concern in international fora.

3. NGOs expressed concern that, in light of commitments made in Tokyo, and the fact that Afghanistan now looks seriously underfunded going into next year, they would like to see the majority of funds made available in the form of grants, not loans.

The issue of overall funding for the reconstruction program is significant. The commitment from the World Bank for Afghanistan is for a total of US\$570m from IDA for a two and a half year period. Of this amount the first US\$100m has been provided entirely as grants. Of the remaining US\$470m, approximately 30 percent will comprise grants with the remainder on IDA's highly concessional terms which provide interest free loans, with a 10 year grace period and 40 year repayment, and a very modest (less than 1\%) administrative charge. The Bank's aim is to assist in Afghanistan's development and we would not wish to create an unsustainable debt situation, so we are working closely with Government and the IMF to ensure that the borrowing strategy is in the interest of the country's longer term development aims.

4. Participants were interested in the anticipated division of resources across the four areas of strategic focus. Additionally the need for the Bank to take a long-term approach to development was stressed noting that most of Afghanistan's problems could not be solved through short term emergency interventions.

$>$ The Bank noted that there is no clear division of resources among the areas of strategic focus. The nature of the issues being addressed will dictate, to some extent, the volume of resources to different areas. In some cases IDA investments will be the main tool of engagement, whereas in others technical assistance and analytical work will be the primary method, thus using less financial resources. The Bank supports fully the long term nature of the development agenda, emphasizing that this strategy represents the next step in a longer involvement in Afghanistan's development. 
5. The importance of taking into account, and building on, the substantial experience of NGOs in Afghanistan, many of which have been operating in the country for many years, was emphasized. There is concern that insufficient attention has been taken to share experiences of those already active on the ground.

$>$ The Bank provides funding to Government for programs, many of which are then implemented by NGOs. The Bank will continue to engage with NGOs, though it should be noted that going forward the challenge for NGOs will be to ensure alignment with Government programs.

6. Several NGOs expressed concerns regarding the National Solidarity Program particularly its scope and speed of delivery, arguing that to be effective, community development takes substantial amounts of time.

$>$ The Ministry of Rural Reconstruction and Development has held in-depth discussions with NGOs on the NSP and has taken on board suggestions received and further discussions are planned. Current plans clearly recognize the valuable role that NGOs will play in implementation of this program. The Bank is committed to a long-term role in community development and, as well as building on experiences of organizations active in Afghanistan, is also taking into account international experience in helping design programs for Afghanistan.

7. While the Bank's direct support to Government was noted and appreciated by participants, the need for monitoring mechanisms that ensure transparency, accountability and quality was emphasized, including independent external monitoring. There is also a need to assess impacts of programs which can feed into future strategies.

$>$ The Bank agrees fully with this view and is working with the Government to assist in this regard. In addition to monitoring Bank-funded projects, the Bank is also working to develop government capacity in key areas, such as financial management, to enhance accountability. Furthermore a key feature of the NSP is the use of external monitors.

8. Gender issues need to be addressed in ways that take into account local cultural norms. Education and health are the main ways to reach women in a widely acceptable manner, and many networks are being established which can be used to reach out - such as the network of traditional birth attendants. Additionally it is important to take into account regional differences and not assume that the same methods will be applicable in all parts of Afghanistan.

The Bank has initiated a Gender Assessment which will take health and education as its starting point. The assessment will be carried out through a participatory process, and the inputs of those with experience in these issues will be very useful.

9. Noting the Bank's focus on livelihoods, questions were raised whether drug eradication be addressed in the livelihoods program.

$>$ The Bank is mindful of the issue but is not directly involved in drug eradication programs. However it should be noted that under the NSP (which receives Bank funding), all investments that would support production of drug crops or processing of such crops are on the negative list. Furthermore, the labor intensive public works 
program (also supported by the Bank) could-potentially, if taking place during the peak periods of labor requirement for poppy cultivation-provide alternative employment that could draw labor from the poppy harvest (provided the daily wages offered are competitive).

10. Problems surrounding civil servants' salaries and payments, and involvement of the Bank with the Civil Service Commission, were raised.

$>$ The Bank noted that civil service reform is a key issue, but also a complex one that must be addressed carefully so as not to establish the wrong incentives. This is a priority area in which the Bank has already provided significant support to Government, and will continue to do so.

11. Disarmament, Demobilization and Reintegration (DDR), with a focus on Reintegration, should be a priority for the international community. The Bank was urged to integrate DDR in its strategy for the future.

$>$ There is a lot of donor interest in DDR. The Bank has restrictions on any involvement in military activities but is however playing its part through broader program. For example rural public works projects are reaching ex-combatants. The Bank's strategy is to mainstream approaches and not to focus on specific groups such as those involved in the drug trade, ex-combatants, or returning refugees, but rather to address the broader needs of communities. One reason for this is to not contribute to disparities and inequities.

12. The lack of a functioning banking sector is the major constraint to private sector development. Mor eover, the lack of access to capital and adequate insurance services were noted as major concerns for most Afghan entrepreneurs.

$>$ This is another area of strategic focus for the Bank. Building on efforts to date, the focus will be on assisting the Government to provide an appropriate environment for development of a commercial banking sector rather than encouraging direct public sector implementation. The International Finance Corporation (IFC), the Bank's private sector arm, is involved in activities to support the commercial banking sector (see Annex 11).

13. Problems of Government bureaucracy and red tape, the non-payment of contracts, lack of clarity on tariffs and the absence of access to legal support in the private sector's dealings with the Government were cited as key concerns for private sector development. The current state of infrastructure also impedes private sector growth. The destruction of Afghanistan's industrial parks, coupled with constant power outages and the need for expensive power generation equipment, are a major additional cost for the private sector in Afghanistan. Furthermore, incredibly weak telecommunications systems make running a business close to impossible.

$>$ The Bank hopes to work with the Government to improve some of the areas mentioned. However, as noted above and based on international experience, the key will be not to have Government as the implementer, but rather as the regulator and policy maker. It is also hoped that initiatives by IFC, and the Multilateral Investment Guarantee Agency (MIGA) can also provide benefits to private sector growth. 
14. The very pressing issues of drought and its impact on urban migration, were raised, highlighting the need to consider sustainable development in programs being implemented. Additionally, given the country's high dependence on agriculture the importance of attention to this sector was stressed.

$>$ As noted in the TSS the Bank's immediate focus in this area will be on water resources management. Other aspects of sustainable rural development will address issues of livelihoods in rural communities.

15. Questions were raised about the Bank's potential involvement in the justice sector and why it does not plan to address human rights as a cross-cutting theme, while stating it supports the National Development Framework within which human rights is a cross cutting issue.

$>$ The Bank's Articles do not allow it to engage in political activities - an area encompassing human rights. However, community empowerment such as through our support for the CDD program equips poor people, including women, with tools to acquire the rights they seek.

16. Apart from "improving livelihoods", which seems focused on development issues, there is no funding for social service reform such as health, education, etc. These areas will be critical in the coming year.

$>$ The Bank fully agrees that improvements in health and education are vital to Afghanistan's development and is providing support in these areas through two IDA grants (one currently under implementation and the other at an advanced stage of preparation). In line with the Government's NDF and based on significant interest from other donors in funding these sectors, in the future the Bank plans to focus its assistance on less-served areas as explained in the strategy.

\section{Participants}

Representatives of the following organization and agencies participated in the consultations:

\section{Government}

Ministry of Planning

Ministry of Foreign Affairs

Ministry of Agriculture

Ministry of Women's Affairs

Ministry of Reconstruction

Ministry of Urban Development

Ministry of Finance

Da Afghanistan Bank (central bank)

NGOs: coordinated by the Agency Coordinating Body for Afghan Relief (ACBAR) participants included:

Solidarities

Handicap International

Afghan Development Association (ADA)

Danish Committee for Aid to Afghan Returnees (DACAAR)

CARE International

Coordination of Humanitarian Assistance (CHA) 
IBNSINA

Agency for Rehabilitation and Energy Conservation in Afghanistan (AREA) Coordination of Afghan Relief (CoAR)

Peace Winds - Japan

International Assistance Mission (IAM)

World Vision

\section{Bilateral Representatives}

Embassy of Germany

Danish Representative Office

SDC

Embassy of Sweden

Embassy of France

Embassy of Norway

Embassy of Turkey

Embassy of Russia

Embassy of Italy

Embassy of Japan

Department for International Development (UK)

European Commission

Embassy of the United States

Private Sector members of the Kabul Chamber of Commerce including:

\section{Milad Co. Ltd}

Mut Co-Afg Ltd.

Zia Walid Ltd.

Mohmand Co. Ltd

Farabi Co. Ltd 


\section{Annex 2 \\ The Structure and History of Public Administration}

1. Formally, Afghanistan is a unitary state with a remarkable degree of centralization, administratively and fiscally. In principle, the relationship between subnational entities and Kabul is one of very modest deconcentration.

2. Since its inception in 1747, the architecture of the state of Afghanistan has been constantly evolving. The basics of the current arrangements are most readily seen in the foundations that the Afghan Amir, 'Abd al-Rahman Khan (1880-1901) laid down. The Amir used military force to conquer all the territory of Afghanistan and initiated revenue collection from traders and farmers. He codified customary practices and insisted on the application of a uniform code of law throughout Afghanistan. He initiated a complex set of fiscal and administrative arrangements that bound the districts and provincial capitals to Kabul. In this way, the seeds of a highly centralized state were sown.

3. The 1924 Constitution made primary education compulsory for all Afghan childrenbringing all schools under the control of the central government-and sanctioned the collection of taxes as a prerogative of the central government, and completion of an annual budget as one of its key responsibilities. Sector ministries were established in Kabul in the reign of Amir Shir 'Ali Khan (1863-65 and 1868-79). The ministries in Kabul established branch offices in the provinces, establishing the principle that the provincial administrations are the local representative of central government. When the new Constitution was passed in 1964, the Afghan state's unitary nature was fully endorsed.

Box 1: - The Structure of the Executive

There are at least four types of subnational government entity in Afghanistan:

- 32 provinces (Wolayat)

- 326 districts (Uluswali) - with each province containing between 5 and 20 districts

- Provincial municipalities (Sharwali Wolayat) are self-standing entities, with a mayor with each province in principle containing one such municipality

- Rural municipalities (Sharwali Uluswaly) have some distinctive features but are largely departments of the district - with each district containing at most one rural municipality, but some with none.

4. The onset of conflict starting in 1978 stopped any further consolidation of central authority-but the administrative and fiscal structures of the state have proven to be resilient. Three decades of war have not led to state collapse. They certainly led to the collapse of legitimate political authority and the usurpation of political authority by local commanders and warlords, but the fiscal and administrative arrangements still provided a glue that held many aspects of the state together.

5. Reconstructing the state - building on strengths: Afghanistan has three key strengths that should be capitalized on in rebuilding the public sector. 
6. The basic laws are sound. The existing Budget Law, Accounting Regulations and Treasury Manual, while somewhat complex, are reasonable and provide appropriate checks and balances. The Budget Law provides some elements of very good practice, in particular in its requirement that the full costs of projects should be reflected in the Government's Budget and in the specification that the Auditor General's Office has comprehensive responsibility for compliance auditing across government.

7. The underlying arrangements for government employment stem from the 1970 (SY1349) Law on the "Status and Condition of Government Employees", as amended by the 1977 (SY 1356) Decree No. 1433. This basically sound legislation provided for a system of centralized recruitment and established a system of job classification and grading that provides the underpinning for managing pay policy within the public sector. It is important to note that employment within government is regarded as a homogenous whole. There is no distinction made between employees of a commercial government enterprise and those of a central government ministry. Similarly, there is little effective distinction between the terms and conditions of permanent staff and those on contracts.

8. These laws are well understood and are followed. Primary responsibility for implementing the Budget Law lies with the Ministry of Finance in Kabul and the network of provincial agents of the Ministry in the Provinces - Mustoufie Velayat (also known just as Mustoufie). The existing clerical system for accounting for revenues and expenditures and for establishment control at the provincial and district level has been resilient and appears to be largely intact and to be well understood by staff at every level. The overall state of communications is appalling and is contributing very significantly to problems in the existing system. However, the system is not being respected only in a procedural sense. Formal limits imposed under the system, such as budgetary allocations and establishment limits, are also being respected.

9. On the revenue side, the focus of concerns is, inevitably, on customs. There are operational difficulties because all tariffs are set in Kabul, leading to many delays if the imported good is not on the list of rates provided by Kabul, requiring the customs house to send a sample of the good to Kabul, requesting a new rate. More substantially, however, there are significant political problems with remitting customs revenues to Kabul.

10. Establishment control systems at the central, provincial and district levels, while paperbased and rudimentary, appear to be operating reasonably well. Current salary levels, however, combined with the extreme degree of compression of pay between top and bottom grades, present a serious problem if experienced and qualified professionals are to be attracted and retained in the public sector.

11. The public sector is not bloated. Fig.1 which shows the total number of people for whom salary payments have been made offers a reassuring picture, in which although the total number of staff for whom salaries were paid varies, it never exceeds a maximum of around 240,000 . It shows a drop during the last pay period, primarily in subnational staffing totals, consistent with the problems that many provinces face in bringing their payroll to Kabul for processing. 
Figure 1: Numbers of staff for whom salaries have been paid

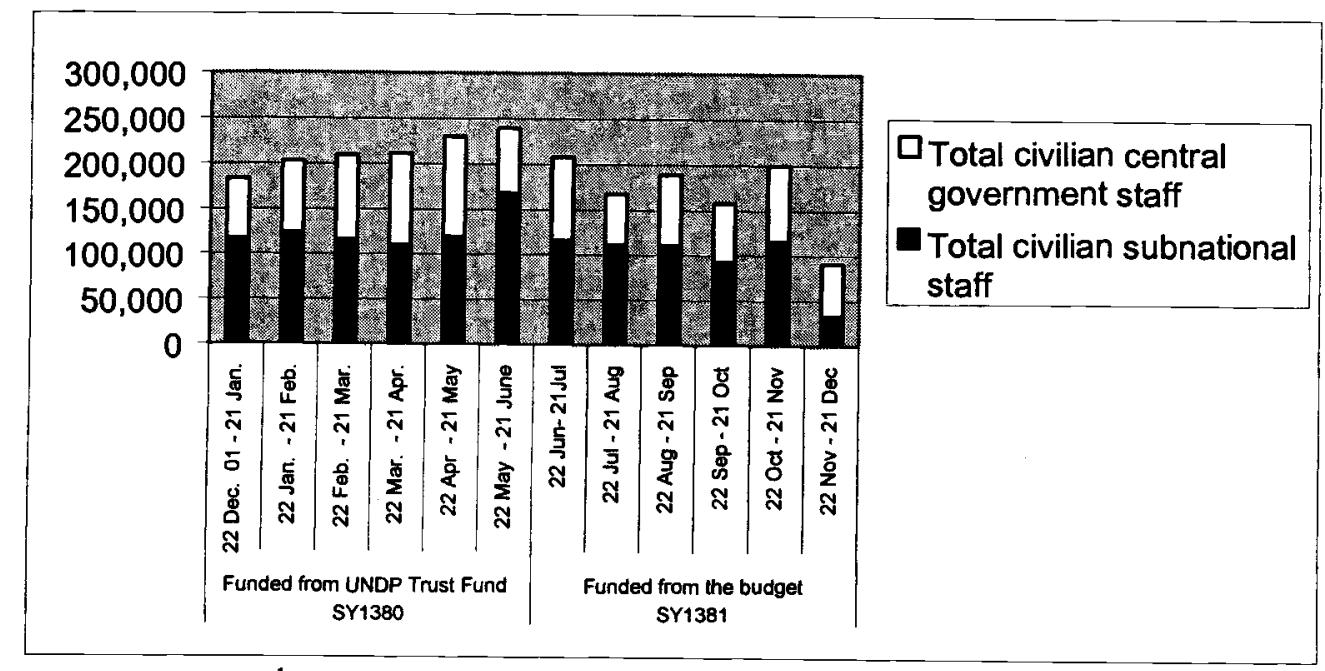

Source: See footnote ${ }^{1}$

12. However, it is possible that the underlying totals might be somewhat larger, as there is considerable variation in the numbers of staff paid each month on each ministry or provincial payroll. Reasonable estimates that allow for this possibility put the total civilian employment at between 240,000 and 330,000. It remains important to emphasize that even the largest of these estimates places Afghanistan at the low end of public employment relative to population. These estimates suggest that the current size of public employment is, in any absolute terms, quite small, at between 0.8 percent and 1.4 percent of the assumed population of 23 million. ${ }^{2}$ However, this must be seen in the context of the weak capacity of government and, relative to its capability, this is not a small government. A large proportion (around 40 percent) of this relatively small workforce is located within Kabul. ${ }^{3}$

${ }^{1}$ Requests for salary payments for the 6 pay periods from 22 December 2001 to 21 June 2002 (inclusive), and received before the July 312002 , were processed and paid by the UNDP before they closed their payroll operation on August 15th. UNDP provided two datasets for payrolls submitted during this period:

- payments made prior to June 30 ;

- payments made between July 1 and August 15.

Requests for salary payments for periods from June 22 onwards were processed by the Treasury Presidency in the Ministry of Finance and funded from the budget. These data, showing payments to 15 January 2003, were collated and provided by PriceWaterhouseCoopers.

${ }^{2}$ In recent years, general civilian government employment (i.e. public sector employment excluding the military and excluding state owned enterprises) has accounted for about $2.5 \%$ of the population in Asia and the Pacific. The estimates of employment for the provinces are not disaggregated between sectors and thus the data do not allow any assessment to be made of the proportion of public sector employment that is in the social sectors (education, higher education and health). $40 \%$ is typical except for the Former Soviet Union where social sector employment averages at around $70 \%$ of general civilian government.

${ }^{3}$ This is potentially very problematic as it suggests that any moves towards adequate staffing in the provinces without corresponding reductions in staff in Kabul could produce a large government - which would be both unnecessary and unsustainable. It will not be easy to persuade existing staff to leave Kabul and work elsewhere. 
6. The basic laws are sound. The existing Budget Law, Accounting Regulations and Treasury Manual, while somewhat complex, are reasonable and provide appropriate checks and balances. The Budget Law provides some elements of very good practice, in particular in its requirement that the full costs of projects should be reflected in the Government's Budget and in the specification that the Auditor General's Office has comprehensive responsibility for compliance auditing across government.

7. The underlying arrangements for government employment stem from the 1970 (SY 1349) Law on the "Status and Condition of Government Employees", as amended by the 1977 (SY 1356) Decree No. 1433. This basically sound legislation provided for a system of centralized recruitment and established a system of job classification and grading that provides the underpinning for managing pay policy within the public sector. It is important to note that employment within government is regarded as a homogenous whole. There is no distinction made between employees of a commercial government enterprise and those of a central government ministry. Similarly, there is little effective distinction between the terms and conditions of permanent staff and those on contracts.

8. These laws are well understood and are followed. Primary responsibility for implementing the Budget Law lies with the Ministry of Finance in Kabul and the network of provincial agents of the Ministry in the Provinces - Mustoufie Velayat (also known just as Mustoufie). The existing clerical system for accounting for revenues and expenditures and for establishment control at the provincial and district level has been resilient and appears to be largely intact and to be well understood by staff at every level. The overall state of communications is appalling and is contributing very significantly to problems in the existing system. However, the system is not being respected only in a procedural sense. Formal limits imposed under the system, such as budgetary allocations and establishment limits, are also being respected.

9. On the revenue side, the focus of concerns is, inevitably, on customs. There are operational difficulties because all tariffs are set in Kabul, leading to many delays if the imported good is not on the list of rates provided by Kabul, requiring the customs house to send a sample of the good to Kabul, requesting a new rate. More substantially, however, there are significant political problems with remitting customs revenues to Kabul.

10. Establishment control systems at the central, provincial and district levels, while paperbased and rudimentary, appear to be operating reasonably well. Current salary levels, however, combined with the extreme degree of compression of pay between top and bottom grades, present a serious problem if experienced and qualified professionals are to be attracted and retained in the public sector.

11. The public sector is not bloated. Fig.1 which shows the total number of people for whom salary payments have been made offers a reassuring picture, in which although the total number of staff for whom salaries were paid varies, it never exceeds a maximum of around 240,000 . It shows a drop during the last pay period, primarily in subnational staffing totals, consistent with the problems that many provinces face in bringing their payroll to Kabul for processing. 
Figure 1: Numbers of staff for whom salaries have been paid

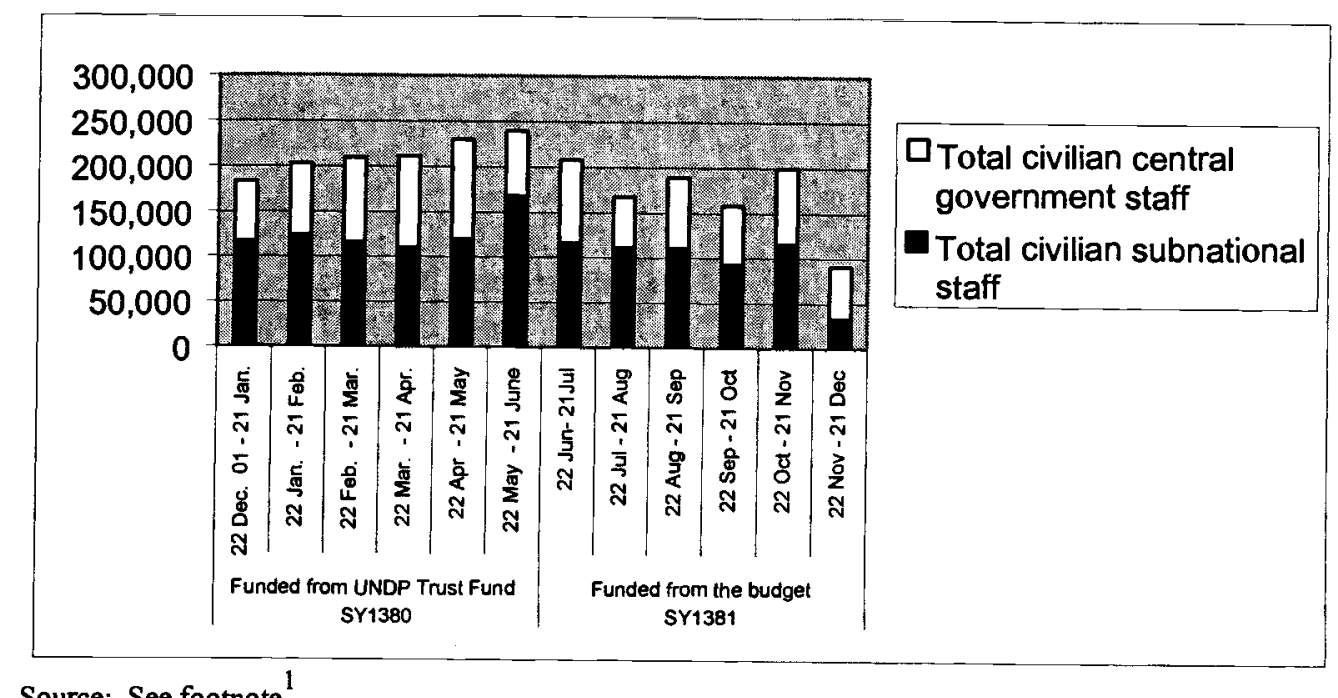

Source: See footnote ${ }^{1}$

12. However, it is possible that the underlying totals might be somewhat larger, as there is considerable variation in the numbers of staff paid each month on each ministry or provincial payroll. Reasonable estimates that allow for this possibility put the total civilian employment at between 240,000 and 330,000 . It remains important to emphasize that even the largest of these estimates places Afghanistan at the low end of public employment relative to population. These estimates suggest that the current size of public employment is, in any absolute terms, quite small, at between 0.8 percent and 1.4 percent of the assumed population of 23 million. ${ }^{2}$ However, this must be seen in the context of the weak capacity of government and, relative to its capability, this is not a small government. A large proportion (around 40 percent) of this relatively small workforce is located within Kabul. ${ }^{3}$

\footnotetext{
${ }^{1}$ Requests for salary payments for the 6 pay periods from 22 December 2001 to 21 June 2002 (inclusive), and received before the July 312002 , were processed and paid by the UNDP before they closed their payroll operation on August 15th. UNDP provided two datasets for payrolls submitted during this period:

- payments made prior to June 30 ;

- payments made between July 1 and August 15.

Requests for salary payments for periods from June 22 onwards were processed by the Treasury Presidency in the Ministry of Finance and funded from the budget. These data, showing payments to 15 January 2003, were collated and provided by PriceWaterhouseCoopers.

${ }^{2}$ In recent years, general civilian government employment (i.e. public sector employment excluding the military and excluding state owned enterprises) has accounted for about $2.5 \%$ of the population in Asia and the Pacific. The estimates of employment for the provinces are not disaggregated between sectors and thus the data do not allow any assessment to be made of the proportion of public sector employment that is in the social sectors (education, higher education and health). $40 \%$ is typical except for the Former Soviet Union where social sector employment averages at around $70 \%$ of general civilian government.

${ }^{3}$ This is potentially very problematic as it suggests that any moves towards adequate staffing in the provinces without corresponding reductions in staff in Kabul could produce a large government - which would be both unnecessary and unsustainable. It will not be easy to persuade existing staff to leave Kabul and work elsewhere.
} 
13. These estimates suggest that the current size of public employment is in absolute terms, relatively small, at between 1 percent and 1.3 percent of the assumed population of 23 million. ${ }^{4}$ However, this must be seen in the context of the lack of effective government. Relative to its capabilities, this is not a small government. A large proportion (between $42 \%$ and $51 \%$ ) of this relatively small workforce is located in Kabul. ${ }^{5}$

\section{Ways forward}

14. The key principle that must underpin all assistance to the public sector is to work with the strengths of the system, nurturing the discipline that has remained despite the many years of conflict. This means respecting and strengthening the budget process, as the central vehicle for coordinating and communicating government policy, and supporting the management structures and the authority of ministers and their senior staff.

15. Respecting the traditions of the Afghanistan budget process means respecting the hierarchical authority of Kabul. While central government ministries and institutions are primary budgetary units with specific budgets determined by law, the provincial departments of the central government ministries are secondary budgetary units and thus should receive allocations at the discretion of the ministry. Districts are tertiary budget units and thus their budgetary allocations depend on the decisions made by the relevant provincial level departments (secondary budget units) of the Kabul ministries (primary budget units). Supporting management structures means avoiding the distracting impact of uncoordinated top-ups and incentive payments. In the health sector in particular, poor pay for doctors and other health professionals has already led to a proliferation of top-ups from donor agencies and NGOs. When staff receives incentive payments from NGOs and others that are far larger than their public sector salaries, this creates serious management difficulties.

16. The policy priorities that the Bank is supporting through the Emergency Public Administration Project, and through its technical assistance, include:

- Accelerating the execution of the budget, particularly in the provinces. The credibility of the central government depends on its ability to implement the budget, not just in Kabul but nationwide.

- Ensuring timely payment of salaries. Pay for all staff, including those in the provinces, should be provided regularly and on a timely basis to all staff on the nominal roll. It is important that some discipline is introduced into the payroll system, both to facilitate fiscal planning and reduce the risks of fraud.

- Improving the quality of budget preparation. The budget must be the mechanism for control of public expenditures. While the situation in SY1381 was fluid, it is essential that the SY1382 represent a true budget to which the authorities adhere.

- Ensuring fiscal transparency. Regular reporting on budget execution will show that government remains committed to its own principles. Publication of a comprehensive audit is a key element.

$4 \quad$ In recent years, general civilian government employment (i.e. public sector employment excluding the military and excluding state owned enterprises) has accounted for about $2.5 \%$ of the population in Asia and the Pacific.

${ }_{5}$ This is potentially problematic as it suggests that any moves towards adequate staffing in the provinces without corresponding reductions in staff in Kabul could produce a large government - which would be both unnecessary and unsustainable. It will not be easy to persuade existing staff to leave Kabul and work elsewhere. 
- Achieving customs reform. Revenue collection targets are important as Afghanistan needs to be able to self-finance its recurrent budget. Customs receipts are the largest source of revenue.

- Assisting in the creation of a Senior Civil Service. Ministries and departments need effective and stable leadership, committed to rapid implementation of programs and to a participative approach in policy development.

- Supporting the establishment of a lead agency for civil service reform. The creation of the Senior Civil Service, pay reforms, reform of recruitment processes and the relocation of serving central and provincial administration employees whose skills are no longer needed, requires strong central leadership.

- Regulation of top-ups. Salary top-ups and other direct payments from donors to serving government staff distort incentives and create severe difficulties for government managers. It is important to provide guidelines for additional pay that donors and other organizations may provide to public employees working as partners in key development projects.

- Building a database of government employees. The difficulties of creating a coherent payroll system are self-evident, and the Government has made significant steps forward. However, all likely next steps, including pay reform, restructuring of government ministries, and automation of payroll can only be achieved when government is in a position to specify the people in whose names salaries are being paid.

- Establishing realistic employment caps. Schedule 4 to the 1381 budget provided an initial list of ministry headcount ceilings. This is a crucial component in constraining any tendency toward excessive hiring. However, the 1381 budget ceilings did not distinguish between province and ministry staff, leading to difficulties in enforcement of a hard constraint. The 1382 budget should have a set of enforceable ceilings.

- Differentiating employment in government enterprises from the larger public sector. In the longer term, if public enterprises are to be provided with greater flexibility in remuneration then new contracts for their staff will be necessary that remove government enterprise staff from the civil service and place them on new employment contracts directly with their employing enterprise. 


\section{Annex 3 \\ IDA Grant Funded Projects and Projects Under Preparation}

Four IDA grant funded projects were approved in FY02. An additional two projects are at advanced stages of preparation and planned for FY03 delivery. Below is a summary description of each of these six investments.

\section{Emergency Public Administration Project IDA Post Conflict Grant - US\$10m}

This project is supporting Afghanistan's efforts to lay the foundation for a transparent, well-functioning public administration by facilitating better use of public resources. The grant is financing the employment of international experts who are working with government officials to carry out work in three main areas: procurement, financial management, and audit functions; developing the administration's capacity in these areas; and assessing existing systems and procedures to recommend suitable policy reforms. Achievements on the ground to date include:

- Financial Management. Working closely with the Treasury Department in the Ministry of Finance, the financial management agent has helped computerize the treasury's check issuance system, so the Ministry can now generate accurate monthly expenditure reports, by Ministry, location, and budget code. The next stage of the work will extend to a fuller revenue and expenditure management system, introduce functionality in the Dari language, and introduce customized reporting.

- Audit: Initial computer and language training has commenced, and it is expected that fuller support to enhancing audit capacity will be provided starting in January.

- Procurement. By mid-November 2002, the procurement agent had placed 33 contracts valued at US\$29.6 million for the government. In addition, it was processing 69 additional contracts valued at about US\$65 million.

\section{Emergency Infrastructure Project IDA Post Conflict Grant US\$33m}

This project supports work in the following areas: (i) Urban Services, including rehabilitation of water supply and sanitation networks in secondary cities, solid waste management and sanitation improvements in Kabul, and labor intensive urban public works to generate short-term employment opportunities; (ii) Power, including the provision of critical materials and spare parts for urgent repairs in Kabul and some secondary cities; and (iii) urgent policy and regulatory advice, training and additional engineering support in key infrastructure sectors, including oil, gas, mining and telecom. Achievements on the ground to date include:

- Solid Waste Management in Kabul. Implementation began with the Municipality of Kabul in October 2002 for the collection of thousands of tons of solid waste, which had been lying throughout the city for months. To date project staff have been recruited to work in 12 districts of Kabul. In order to facilitate capacity building and "learning by doing," all project staff are based within the municipality in order to work closely with the sanitation department. Teams of professional female hygiene and health educators will go to each household to speak with families about the correct and safe clearing of their rubbish. The project is being implemented by Habitat, the United Nations Human Settlements Program. 
- Labor Intensive Municipal Public Works. In July 2002, local communities began to meet with project and municipal staff to identify priority public infrastructure works in the five participating cities (Kabul, Kandahar, Jalalabad, Mazar-i Sharif, and Herat). The works are making much-needed repairs while providing short-term employment and will include demolition of destroyed buildings, recycling of rubble involving the recovery of usable building material, clearing of drains, reconstruction of schools and clinics, and the revitalization of urban parks. The program is being overseen by Habitat in coordination with Afghanistan's Ministry of Urban Development and Housing.

- Recommissioning the Northwest Kabul Power Station. Work began in September 2002 to recommission the $45 \mathrm{MW}$ Northwest Kabul thermal power plant, which has remained inactive for 14 years. Both turbines are now operational and are expected to almost double the available power supply in Kabul. The power will be used mainly to heat and light homes and offices and allow street lights to be lit. World Bank grant funds of US $\$ 2.4$ million are being used to procure diesel fuel.

\section{Emergency Public Works and Community Empowerment IDA Post Conflict Grant US\$42m}

This project has four components:

- The Community Empowerment component delivers grants directly to communities for small rehabilitation works and development of community assets aimed at kick starting economic activities. The project underpins the government's National Solidarity Program in bringing assistance to communities across Afghanistan. Community-driven planning has begun in 119 communities in four provinces. First disbursements to communities are expected to begin in January 2003. Preparations are underway to bring the program to the first group of 7,000 communities by March 2003.

- The Labor Intensive Works component is creating employment in rural areas for the needy including ex-combatants and returning Afghans who fled drought and conflict. In October 2002 the project began field surveys, including meetings with leaders of rural communities in more than 20 provinces to determine priorities and prepare projects to repair provincial and district roads. Nine NGOs funded by the Ministry of Rural Rehabilitation and Development have started works in seven provinces (Badghis, Bamian, Faryab, Ghazni, Logar, Nooristan, and Zabul). The Ministry of Public Works has conducted field surveys in 15 provinces, and works began in December. The project is expected to create more than 2 million person days of employment.

- Salang Tunnel Rehabilitation component is providing emergency maintenance and improvement work on the $2.7 \mathrm{~km}$ tunnel, which covers a critical section of the highway that connects the city of Kabul to eight provinces and to both Uzbekistan and Tajikistan. The goal is to secure two-way operation for daytime travel, particularly for the winter when, traditionally, poor ventilation and electricity connections combined with snow and ice accumulation have made the tunnel dark, treacherous, and often impassable. The tunnel is a vital connection between northern and southern Afghanistan and for returning refugees. Besides protecting human lives, ensuring continued safe passage through the tunnel and upgrading the mountain road will help keep down the price of essential goods such as food and clothing. Efforts have been coordinated with the French NGO ACTED, with additional funding from the US Agency for International Development (USAID). 


\section{Emergency Education Rehabilitation Project IDA Post Conflict Grant - US\$15m}

This project is helping to rehabilitate university faculties and facilities, rehabilitate primary schools, support the Ministry of Education in developing education policy and institutional development plans, and establish a government intranet and global distance learning center. Special emphasis has been placed on increasing access to educational opportunities for girls. Achievements on the ground to date include:

- Assistance to the Higher Education Institute. Grants have been provided to the Institute of Polytechnic, the University of Education, the Medical Institute, and five faculties and dormitories of Kabul University to support rehabilitation of buildings and improve the quality of teaching. Grants for rehabilitation of approximately 100 primary schools in three provinces (Bamiyan, Palwan, and Logar) will be provided by the Ministry of Education through NGOs. Physical rehabilitation of schools will be combined with teacher training and other educational inputs. The selection process for the position of Chair of the university's newly established Women's Leadership Department has begun. Funds for the position are being provided by the World Bank President's Contingency Fund.

- Kabul Distance Learning Center. The center has been established at the site of the AACA. Its first international videoconference was held in mid-November and connected experts in Tajikistan, Kazakhstan, Uzbekistan, and Washington, D.C., to discuss the region's economic development prospects. The center is part of the World Bank-established Global Development Learning Network and will facilitate the sharing of development knowledge between Afghanistan and top development officials from around the world through new information and communications technologies.

- Government Internet Connectivity Project. Seven government agencies (Ministries of Finance, Rural Reconstruction and Development, Foreign Affairs, Communication, President's Office, the AACA, and the Central Bank) have been connected to the internet and have access to email for the first time in history. They are also connected to the Kabul Distance Learning Center.

\section{Emergency Transport Rehabilitation Project IDA Credit - US\$108m (proposed)}

The objective of the proposed Emergency Transport Rehabilitation Project is to facilitate the country's economic and social recovery through improved physical access to goods, markets, and administrative and social services. This will be achieved by:

- removing key transport bottlenecks (collapsed bridges, eroded road sections, disintegrated pavements, damaged tunnels, unsafe air traffic operation) that seriously hamper recovery;

- providing equipment and technical assistance related to planning, maintenance and

operations, thereby building capacity in management, implementation and subsequent

maintenance; and

- assisting in the establishment of an institutional and policy framework for the sector for sustainable service delivery in the transport sector.

The removal of key transport bottlenecks will immediately promote regional economic integration and facilitate trade, delivery of humanitarian aid, and reconstruction efforts in all sectors. Normal traffic operations on the key road arteries and in the air will be restored, also 
facilitating movements on the key import/export links and main corridors. Additionally, the civil works and subsequent maintenance financed through the project will provide opportunities for employment through the engagement of the local population in rehabilitation activities.

\section{Health Emergency Rehabilitation Project IDA Credit - US\$15m-60m (proposed)}

Anticipated for Board presentation in FY03, the objectives of World Bank assistance in the health sector are:

- to assist the Government in expanding the delivery of a basic package of health services to Afghans who currently are not receiving urgently needed care;

- allow the Government to increase its stewardship over the sector, including a greater role in financing, by coordinating and overseeing the work of NGOs and other partners through formal agreements; and

- build the capacity of Ministry of Public Health at all levels to direct and oversee the health sector.

The Bank is also discussing with government the possibility of preparing a polio project (approximately $\$ 3.5$ million) using the IDA buy-down approach. 


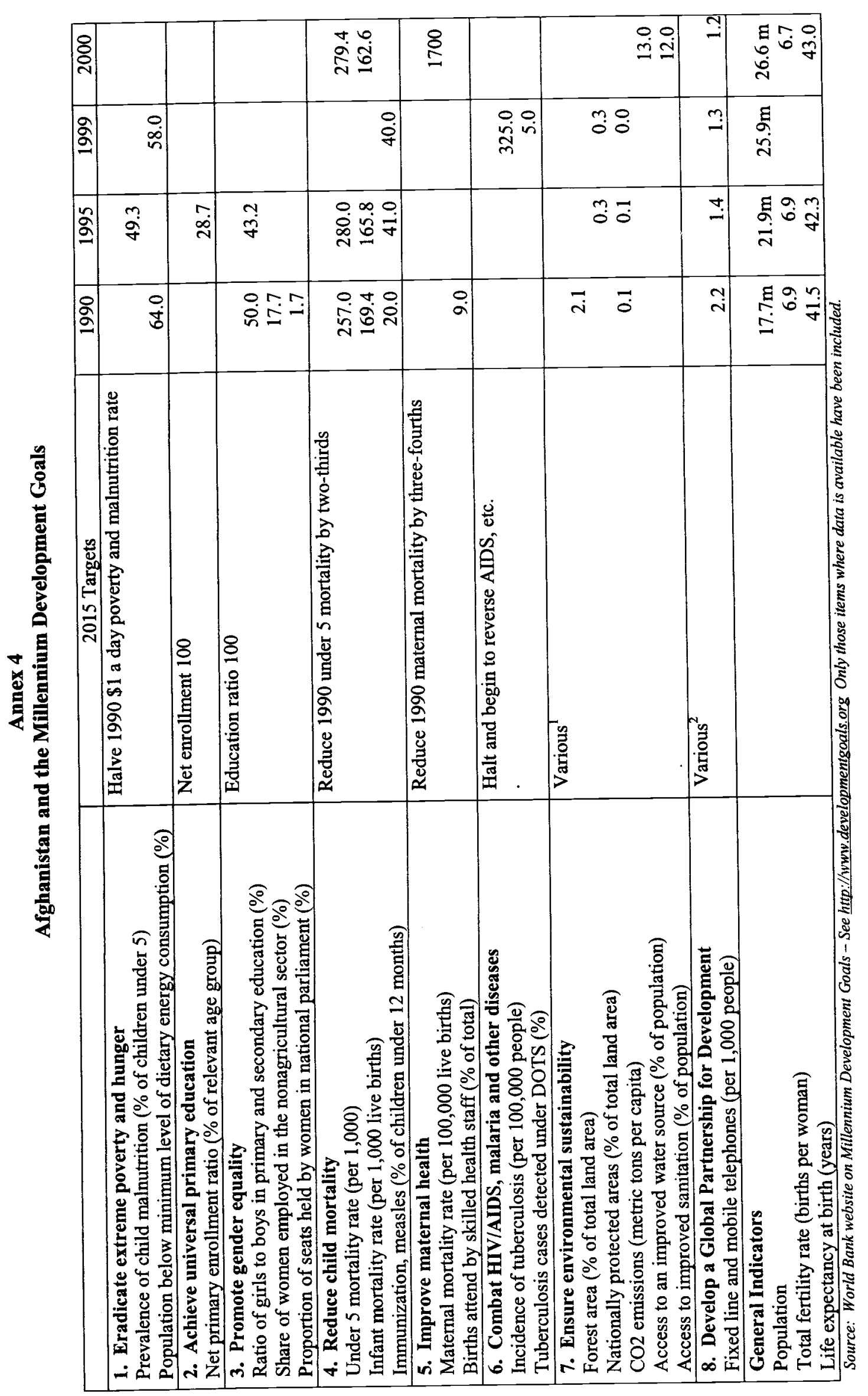

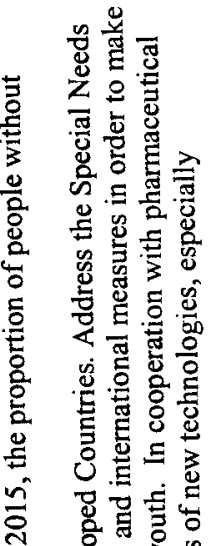
合 응 可 년

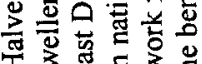

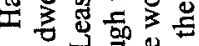

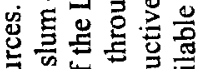
的出娄

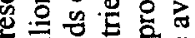

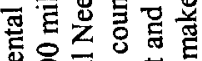

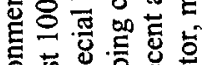

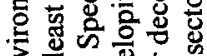
可离总 论 合

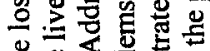

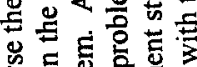

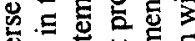
远空造 ह ส .

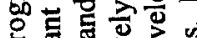

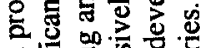

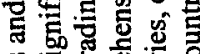
以

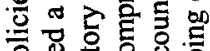
잉 龸言焉言 证

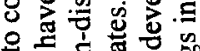

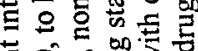

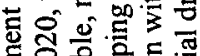

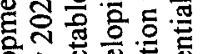
응 六啳

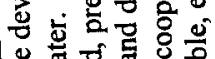

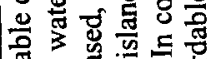

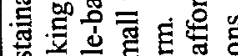

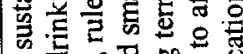

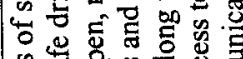
造密

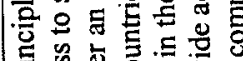

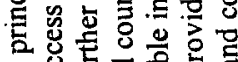
尊

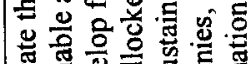

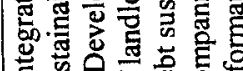

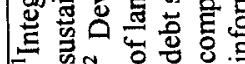




\section{The Establishment of Consultative Croups for Furtherance of the National Development Programme}

Background and Rationale: The 1381-82 National Development Budget was presented by Government to donors at the October 2002 Implementation Group (1G) Meeting. The budget highlights the need for the development of national programmes focused on poverty reduction, gender equity, human rights and national solidarity objectives. The National Budget will remain the central instrument for policy and institutional reform, and the coordination of aid resources to enhance the effectiveness and efficiency with which national programmes are delivered.

The Oovernment has taken the decision, already announced to cooperation partners at the IG, to establish Consultative Groups (CGs) within which the National Budget will be planned, financed and implemented. Each Cunsultative Group will therefore foous on the attainment of specific benchmarks in the areas of policy development, instirutional reform and the programming, implementation and monitoring of specific national programmes. Consultative Groups will allow enhanced government-donor interaction and coordination of efforts in that particular programme area.

The CG structure aims to encourage a fully transparent and accountable process to guide the collaborative reconstruction efforts.

A National Developunent Forwm: Every year in March a meeting of the Afghanistan Development Forum (ADF), will be convened to discuss the budget for the next fiscal year, outlining national priority areas and policy objectives, as well as to assess the progress that has been made in the year before. The ADF will take place in Kabul and cooperation partners will be invited to attend this meeting, which will serve as the first budget hearing. After amendment, the National Budget will be submitted for cabinet approval in March each year prior to the forthcoming fiscal year. A mid-term review meeting will also be organised in the second half of the year to monitor progress.

The Government will convene Consultative Groups which will also report to the $C O$ Standing Committee on budget as well as administrative issues. Regular reporting arrangements are also to be established. The Capacity Building Groups now being established shall eventually provide significant support to the CG process to facilitate the flow of information between $\mathrm{CG}$ meetings and ministries.

What is a Cousultative Group? Consultative Groups, chaired by a lead Ministry, provide the mechanism by which Guvernmenl can engage with donors, UN agencies and NGOs to promote the achievement of specific national programme objectives. As indicated above, there will be a national Consultative Group meeting called the Afghanistan Development Forum (to be beld in March 2003). Consultative Groups shall be established for each National Development Programme (e.g. Consultative Group on Education). 
The COs provide the framework that enables donors to finalise their support to each CG programme atea in consultation with Government stakeholders, and ensure consistency with the National Development Framework.

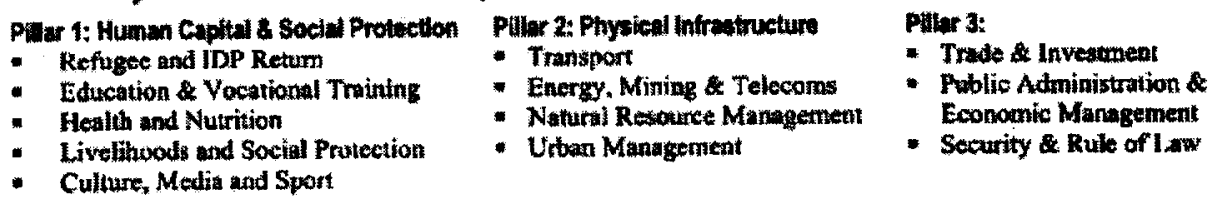

A draft proposal conceming coordination at the provincial level will be submitted in writing to the Government of Afghanistan. The Government of Afghanistan will consider this proposal and determine how it relates to existing coordination mechanisms oullined in this note.

What is the Overall Objective of CGs? The overall objective of the CG process is to increase the effectiveness and efficiency of aid coordination in support of the attainment of national development and poverty reduction objectives through the implementation of the national budget.

How Many Consultanive Groups Will There Be? A total of 12 Consultative Groups will be established covering the twelve National Development Programmes defined within the National Development Framework. Donors and agencies have been requested to focus investments around three of these programme areas where they will, as a result, play key roles. Refugee \& IDP Return and Securily \& Rule of Law are considered cross-cutting areas which do not count among these three choices. Where currenuly progranmed investments are more diffuse, a clear transilion plan should be presented.

In requesting this concentration, the objective is to strengthen the impact of all assistance - in view of extensive nesearch showing that policy and implementation effectiveness is increased with donor focus on a limited range of programme areas. A further motivation is to facilitate Government-led coordination within the $\mathrm{CO}$ struchure. Greater donor focus will ensure that the number of interlocutors for the Chair ministry is reduced to a more manageable number.

All donors are welcome to participate in those CGs which fall within their three focus programme areas, irrespective of the size of their financial contribution. Those donors with very large annual programmes may not wish to limit their involvenent to the three focus areas (plus Refugee \& IDP Retum and Security \& Rule of Law). Such donors may wish to provide substantial support to a fourth or fifh area, taking account of the following:

- the donor has commilted to an annual disbursement of U\$\$30m for programmes and projects presented within the national budget for each of the three existing programme areas, and a further US\$30m per annum for additional programme area, and

- the donor has committed to an annual disbursernent of US $\$ 30 \mathrm{~m}$ to budget support or the ARTF;

\footnotetext{
1 The aational budget covers bolih operating and development expenditures for 1382 and fuane yeart.
} 
What is the Consultative Group Structure? The lead Ministry for each of the 12 NDPs will form and chair a Consultative Group for each sector. This CG will involve a designated Focal Point (see below), and the donor, UN agency and NGO actors most active in the programme area. Donor membership will follow from the concentration in three areas as requested by the Govetnment. The Focal Point donor and/or agency will be designated by the lead ministry.

Each CO will assist in policy management as well as monitoring implementation of activities as envisaged under the National Budget. In particular the CGs will assist in preparing the respective Budget for each coming fiscal year. The $\mathrm{CO}$ will provide a forum for general policy dialogue, monitor the overall implementation of the current budget, report regularly on indicators of progress in the sector, and elaborate detailed national programmes. The CGs, with support from the Standing Committee, will also focus on monitoring performance against benchmarks.

A prograrume Focal Point (secrekary) will be established in each $\mathrm{CG}$ to provide administrative support to the organisation of CG meetings. The Focal Point will be selected through consultation with the Lead Ministry. This role will be played by a donor agency in most cases, although the Focal Point role may also be fulfilled through a donor-UN agency partnership. The existing Programme Secratariats will be replaced by the Focal Point, and the Programme Groups by the COs. Where Programme Secretariats have performed well, the $\mathrm{CO}$ and focal point will build upon these achievements.

The Lead Ministry may prefer to have the Pocal Point role exercised directly by the Ministry, with technical assistance provided by the donor (or donor/agency). This could involve seconding international and national experts to work directly with the Ministry team.

With regards to the CO for Security \& Rule of Law, given the complexity and breadth of issues covered, five Working Groups will be established covering the following components:

- Afghan National Army",

- Demobilisation and Reintegration;

- National Police;

- Justice; and

- Anti-narcotics.

Donors that are particularly active in these areas will be asked if they are willing to assume the Focal Point responsibility (USA, Japan, Germany, Italy, UK, respectively).

What about CG Membership? Membership will be based upon the compatative advantage of specific instilutions (government, donor, agency, and NGO) to contribute towards the enhancement of that particular NDP. Membership will inclusive to allow fur different perspectives and will therefore include:

(i) One lead 'Chair Ministry';

(ii) Government ministries involved in that NDP;

(iii) One focal point donor (or donor/agency partnership); 
(iv) Other donor agencies and International Financial Institutions having that particular NDP among their three priority programmes;

(v) UNAMA and one UN agency; and,

(vi) Two-four NGO representatives (national and intemational).

Terms of Reference for CGs: To guide the activities of each CG, a Terms of Reference (ToR) will be prepared by the Chair ministry and presented to $C G$ members for further discussion and agreement. The Tok will detail both the general and specific responsibilities of $\mathrm{CG}$ members as well as setting clear benclimarks for the preparation and implementation of the national programmes. These benchmarks will be initially based on the results identified under the 1382 National Budget. The ToR will set out the roles of members vis-a-vis the bidget and specify clear submission deadlines for budget and national programme alike. Reporting, including monthly updates of indicators of progress in the sector, and monitoring of benchmarks will also be covered by the ToR.

\section{How ofen will the CGs Meet?}

(i) CGs will met at least monthly at a lime to be jointly agteed with members.

(ii) Extra-ordinary $C G$ sessions can be convened based upon the agreement of over 50 per cent of the members.

Who will convene CG Mecting 7 The lead Government muistry, with the optional assistance of the designated Foeal Point, will convene each meting. Each $\mathrm{CG}$ meeting will be minuted by the Focal Point and circulated to all $C G$ members. Mirutes will also be posted on the AACA website to enable all donors and other assistance partners access.

How will Crass-Cuming Issues be adressed? Tho principal cross-cutting issues foreseen include gender, enviromment, human rights, and humanitarian affairs. These will be mainstreamed where possible into each programme area and reflected in the national budget exercise. An 'Advisory Group' will be established for cach crossculting issue, and meetings held on a monthly basis to help ensure that mainstreaming objectives are attained. The Advisory Groups will feed recommendations into each $C G$ as well as report to the $C G$ Slanding Committee, and ultimately the Afghanistan Development Forum.

Advisory Groups will be expecled to draw up Terms of keference, including elear outpats, such as guidance for line ministries on how best to mainstream cross-cutting issues into their respective components of the national budget. Mimules of the Advisory Groups will, like those of the CGs, be made available through the AACA website.

While COs will be chaired by the Lead Ministry, for advisory groups consideration will be given to appointing a donor or a now-govemmental organisation to the chair role, on the basis of a particular comparative advantage. Membership will be broadbased, with donors, UN agencies, NCOs and other independent organizations, such as human rights organizations, encouraged to participate. Advisory Oroups can discuss with the four national commisstons (Constitutional, Judicial Reform, Human Rights and Civil Service) on how best they can contribute. 
Inclusivity must be balanced against the meed for an effective and informal group. A smaller setting may enhance free discussion. An advisory group of approximately is members is recommended, with members expected to keep close contact with their respective constituencies.

Fach Advisory Group will decide whether a Focal Point (Secretary) is needed, whether a joint Focal Point is appropriate, and whether such a Focal Point should rotate.

Humonitarian Afotrs Auvisory Group. Internationally recognized humanitarian principles, intemational humanitarian law, and the legal bases of a number of donor funding instruments require that certain principles are applied in the delivery of humanitarian assistance. These inchude dolivery of assistance according to need, indepesdence of action, lack of political conditionality attached to humanitarian assistance, accountabitity in the delivery process, and ensuring that delivery of such assistance does not undermine longer-term reconstruction and rocovery.

In order to respect these good governance issues, the Humanitarian Affairs Advisory Group could be chaired by an interuational organization or donor with particular expertise in bumanitarian affairs. Fffective coordinetion with the Covernment partners would be ensured by inviting the responsible Govemment ministries to participate as mombers of the Advisory Growp. The Humanitarian Afturs Advisory Group will meet as often as required by donors in orler to achieve its objectives.

Wh the Standing Committee Continue? The Standing Committce of the IG will become the CG Standing Committee. The Government will ebair the COSC, supported by a joint-secretariat of the AACA and the Netherlands. Meetings will be held on the first Thursday of each month covering macro policy and implementation issues.

For further informadion or quertes about the $C G$ process parrwors are raquested to comect the relewan Dowor Ald Coordination Ofincer at AACA, or other advisors Indicaded in Annex 1. 


\section{Annex 1. Aid Coordination Officers by Donor}

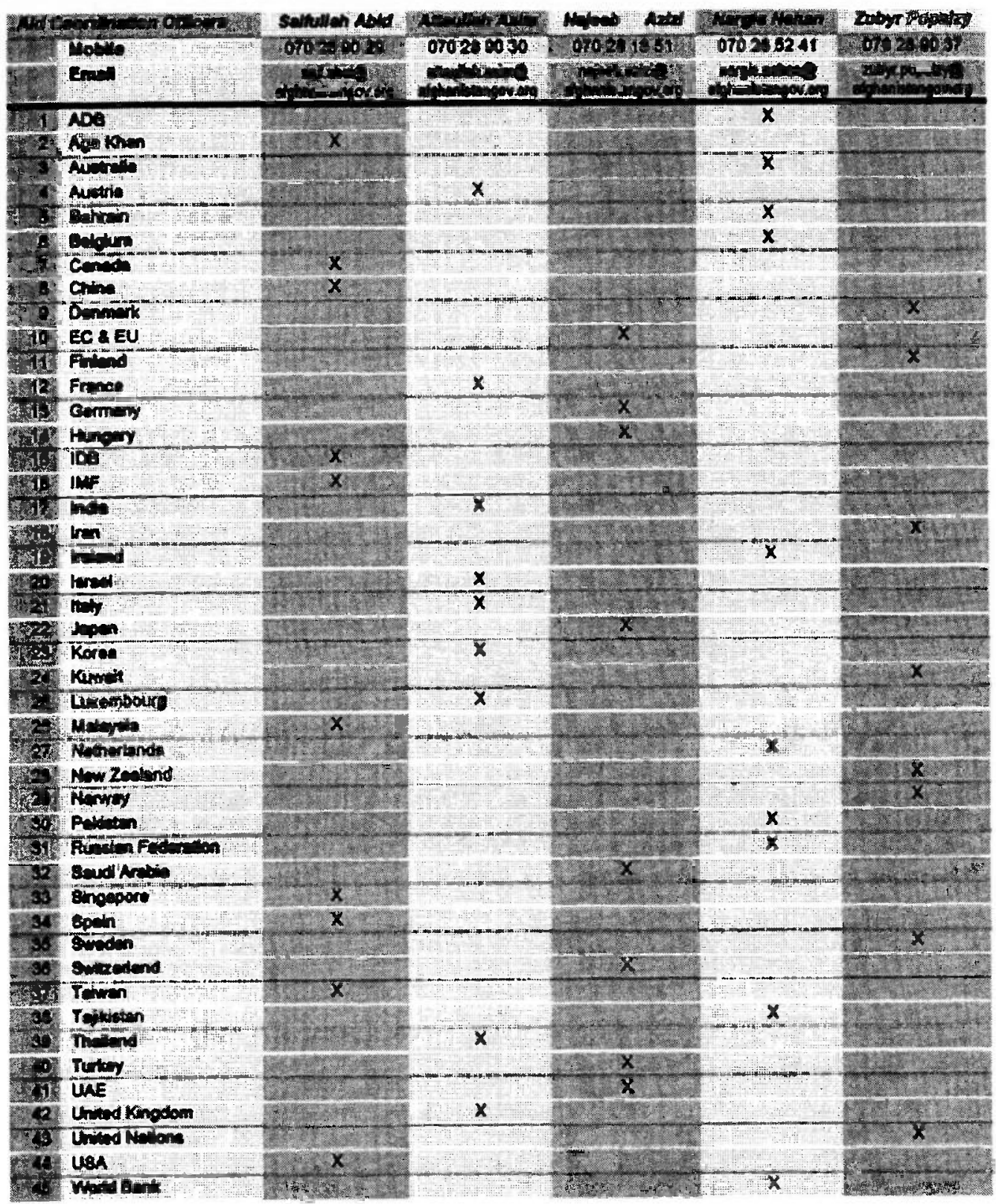


Annex 5

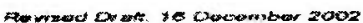

Other Coordination Focal Poiryt:
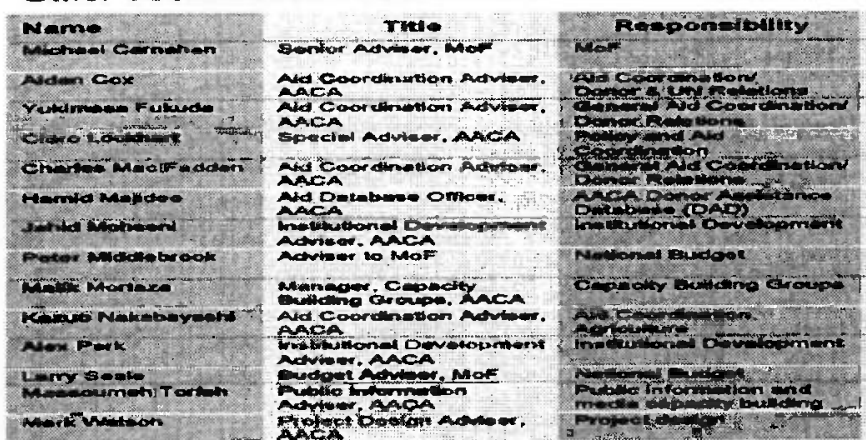

nobill: 0T0 280100 07027 ar $070 \leq \pi 320$ 0702007 ax 67ั0"28 007 OTiO 200020 0 oro $27 \mathrm{sin}$ oroztan ro 07028307 $0>0204115$ oTo 27 6T 31

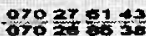
oro 207470

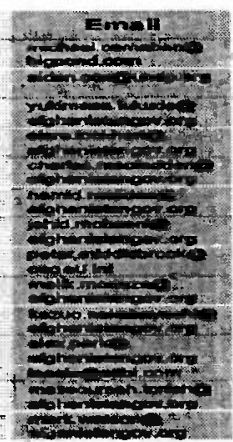




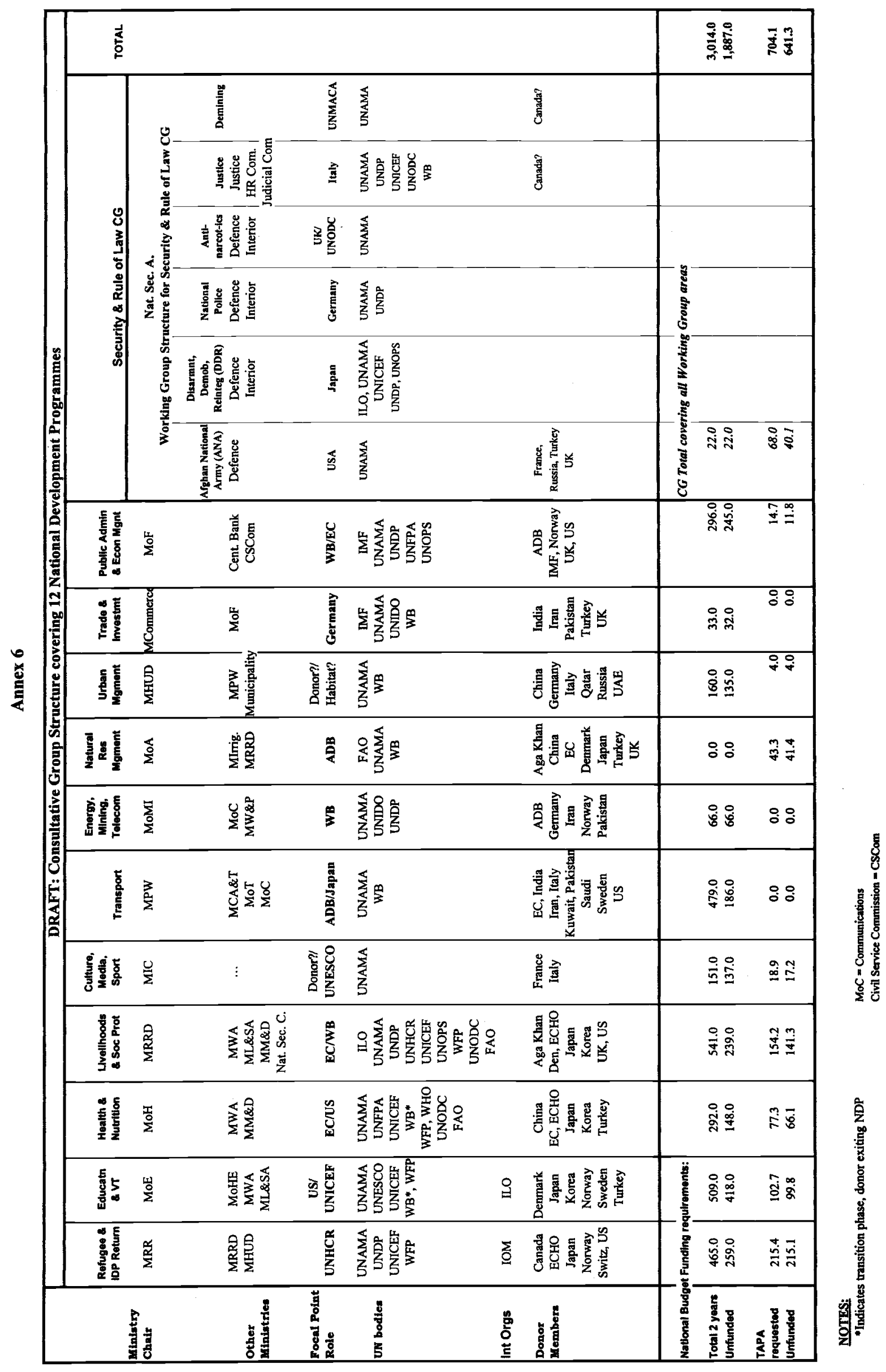




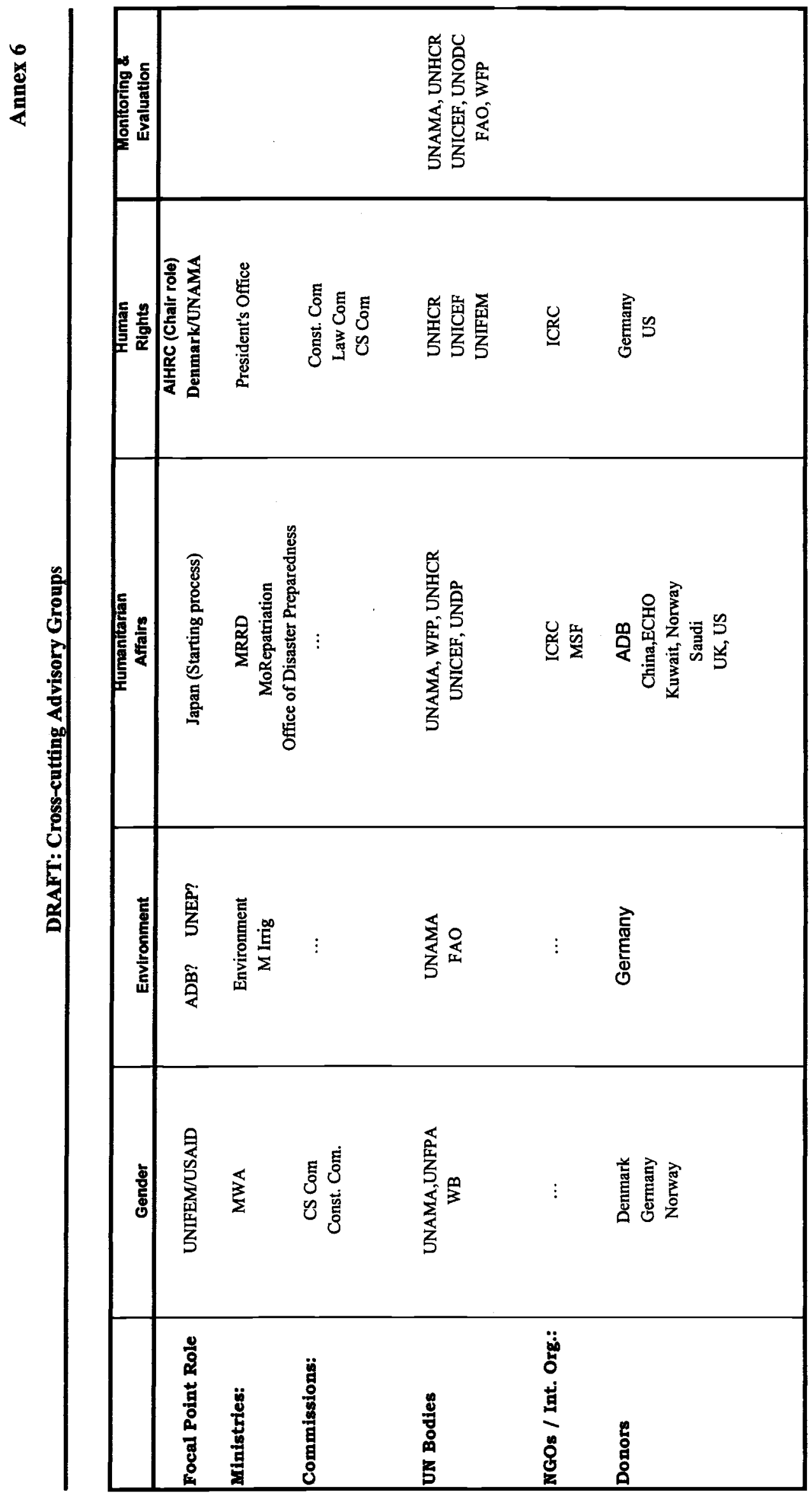


Annex 7

The Post Conflict Fund

1. During the period before the Bank re-engaged in Afghanistan, although lending operations ceased, the Bank was involved in a number of activities and interacted closely with the rest of the assistance community, so as to be prepared for reconstruction. These efforts were important in allowing reconstruction to proceed rapidly once re-engagement became possible. Preparatory activities, which are described in more detail in the first TSS, included continuous monitoring of political and economic developments; managing selective investments in the Afghan refugee communities, working closely with the UN and donors; undertaking knowledgebuilding and knowledge-sharing activities; and providing analytical and strategic depth for the work of the wider assistance community.

2. Contributions by the Post Conflict Fund (PCF), which has been providing assistance to Afghanistan since its establishment in 1998, have been important in allowing the Bank to lay the groundwork for subsequent reconstruction activities. The PCF initially financed a Watching Brief in the country, and later Educational Initiatives for Afghan refugees in Pakistan, with a particular focus on female teachers and students. PCF assistance to Afghanistan dramatically accelerated in the aftermath of the September 11,2001. Before other bilateral and multilateral aid became available, the PCF provided immediate funding to support the designing of the Country Reconstruction Strategy with Afghan and other stakeholders participation. At a later stage, the PCF funded a Launch Package for the Community Empowerment Program in Afghanistan, and the Priority Sector Support and Reconstruction Program. With total approvals of \$5.2 million in Afghanistan grants over FY98-02, the PCF has played a critical role in providing urgent financial resources to the country, often in the absence of any other financing instruments. Additionally, the PCF has served as a funding bridge before substantial bilateral and multilateral resources became available.

\begin{tabular}{|l|r|c|}
\hline \multicolumn{1}{|c|}{ PCF Grant } & Amount USS\$ & Date \\
\hline Afghanistan - UNDP Watching Brief & 350,000 & $12 / 18 / 97$ \\
\hline $\begin{array}{l}\text { Afghanistan - Female Teacher in-service Training (in } \\
\text { Peshawar, Pakistan) }\end{array}$ & 300,000 & $5 / 10 / 01$ \\
\hline Teacher training programs for Afghan refugees & 930,000 & $5 / 10 / 01$ \\
\hline Balochistan Refugee Teacher Training Project & 270,000 & $5 / 10 / 01$ \\
\hline Afghanistan - Enhancing Knowledge and Partnerships & 365,000 & $11 / 19 / 01$ \\
\hline $\begin{array}{l}\text { Reconstruction Strategy for Afghanistan with Afghan } \\
\text { and other stakeholder participation }\end{array}$ & 860,000 & $11 / 19 / 01$ \\
\hline Afghanistan Priority Sectors Support Program & $1,340,000$ & $4 / 4 / 02$ \\
\hline $\begin{array}{l}\text { Afghanistan Launch Package for Community } \\
\text { Empowerment Program }\end{array}$ & 760,000 & $4 / 4 / 02$ \\
\hline Total & $\mathbf{5 , 1 7 5 , 0 0 0}$ & \\
\hline
\end{tabular}


Annex 8

Afghanistan Reconstruction Trust Fund

\begin{tabular}{|c|c|c|c|}
\hline Donor & Pledges to Date * & $\begin{array}{c}\text { Contribution } \\
\text { Received (US\$) } * * * \\
\end{array}$ & $\begin{array}{l}\text { Additional } \\
\text { Funds Under } \\
\text { Processing } \\
\text { (US\$) })^{* * *}\end{array}$ \\
\hline Bahrain & US\$500,000 & $\$ 500,000$ & \\
\hline Canada & $\mathrm{CAD} \$ 19,000,000$ & $\$ 11,936,000$ & $5,500,000$ \\
\hline Denmark & US $\$ 5,000,000$ & $\$ 5,000,000$ & \\
\hline European Union & Euro $30,000,000$ & $\$ 15,000,000$ & $\$ 15,000,000$ \\
\hline Finland & Euro $1,700,000$ & $\$ 2,806,481$ & \\
\hline Germany & Euro $10,000,000$ & $\$ 10,068,400$ & \\
\hline Greece & To be determined & $\$ 0$ & \\
\hline India & US $\$ 200,000$ & $\$ 200,000$ & \\
\hline Iran & US $\$ 1,000,000$ & $\$ 0$ & $\$ 1,000,000$ \\
\hline Ireland & US $\$ 1,000,000$ & $\$ 1,000,000$ & \\
\hline Italy & US $\$ 17,000,000$ & $\$ 17,000,000$ & \\
\hline Japan & US $\$ 5,000,000$ & $\$ 5,000,000$ & \\
\hline Korea & US $\$ 1,000,000$ & $\$ 2,000,000$ & 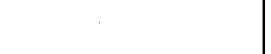 \\
\hline Kuwait & US $\$ 15,000,000$ & $\$ 5,000,000$ & $\$ 10,000,000$ \\
\hline Luxembourg & US $\$ 1,000,000$ & $\$ 1,000,000$ & \\
\hline The Netherlands & Euro $35,000,000$ & $\$ 33,666,500$ & \\
\hline Norway & NOK $14,000,000$ & $\$ 6,868,578$ & \\
\hline Portugal & US\$750,000 & \$0 & $\$ 750,000$ \\
\hline Saudi Arabia & US $\$ 5,000,000$ & $\$ 10,000,000$ & \\
\hline Sweden & SEK $30,000,000$ & $\$ 2,985,000$ & \\
\hline Switzerland & SF $1,000,000$ & $\$ 677,186$ & \\
\hline Turkey & US\$500,000 & $\$ 500,000$ & \\
\hline United Kingdom & GBP $100,000,000$ & $\$ 15,078,500$ & \\
\hline United States & US\$5,000,000 & $\$ 5,000,000$ & $\$ 33,000,000$ \\
\hline Total (US\$) & $\$ 157,794,078$ & $\$ 151,286,645$ & $\$ 65,250,000$ \\
\hline & & $\frac{\text { Total Commitments }}{\text { (US\$) }}$ & $\$ 216,536,645$ \\
\hline
\end{tabular}

*Amounts listed in original currency. Total Pledge based on Exchange Rates as of January 29, 2002. Pledges to be distributed in various tranches. The table lists only those pledges which have been formally confirmed as of 5 February 2002. Discussions are underway with donors who have indicated their intent to contribute to the ARTF.

***Amounts may include additional commitments.

****Amounts may include additional commitments. 


\section{Annex 9 \\ The Twelve National Programs of Afghanistan's National Development Framework}

1. The following provides a summary of the twelve national programs of the Government's National Programme for Reconstruction. Information has been taken from Government documents including the National Development Framework and the National Development Budget.

2. Refugee Return: With an unprecedented number of refugees returning to Afghanistan and settling in urban centers, facilities and services - already severely pressed to serve current residents - are being stretched beyond capacity. This program aims to improve information, registration and documentation for refugees, and provide support to the neediest and their host communities. Specific measures are being taken to cater to the needs of the most vulnerable during the cold winter months. The program will also address policy and institutional issues and develop the capacity of government agencies charged with assisting refugees and coordinating their reintegration.

3. Education: Given the appalling conditions of the education system in the country, evidenced by the population's education indicators - among the worst in the world-and the destruction of much of the country's educational institutions, development of the education system is a vital need for future growth and development in Afghanistan. The education program covers a range of essential areas including policy reform, improving education infrastructure, teacher development, increased primary and secondary school enrolment with a particular focus on female enrollment, as well as vocational training and early childhood development.

4. Health and Nutrition: Suffering from excessively high infant, child and maternal mortality rates as well as the prevalence of communicable diseases and poor nutrition, the health situation for much of Afghanistan's population is very bad. This program will focus on decreasing mortality rates through provision of a basic package of health services, and increasing the capacity of government to develop necessary systems and policies, as well as implementing a number of specific interventions including safe motherhood, and nutrition. Issues of civil service reform and financial planning and management are also key priorities. The expected results are quantifiable improvements in health indicators as well as improvements in health infrastructure and institutional capacity within relevant agencies.

5. Livelihoods and Social Protection: Aimed to address the risk and deprivation experienced by large parts of the rural Afghan population, this program will focus on five areas: institutional strengthening, macroeconomic regeneration, community-based development, protection of lives and livelihoods and income generation. It is hoped that these activities will support sustainable rural livelihoods and, through the National Solidarity Program and Emergency Public Works Program, identified as a priority sub-program for immediate implementation, citizens and communities will be empowered through directly designing and implementing reconstruction efforts in their communities. This program will also address issues of the disabled who comprise nearly $4 \%$ of the population.

6. Cultural Heritage, Media and Sports: Recognized as a key element in consolidating a common Afghan identity, particularly during the transitional period, this program will promote a number of activities including the preservation of Afghan cultural heritage, rehabilitation of sports infrastructure, and rehabilitation of the media, with participation of women encouraged in all areas. 
7. Transport and Telecommunications: The vital role of good communication and transport networks to economic development and national integration form the basis of this program. Suffering significant destruction and neglect through years of war, large investments are planned in these networks. In addition to physical infrastructure, this program will also create a regulatory environment to promote private sector participation in the transport sector and address policy and institutional issues. In the area of telecommunications, telephone, IT, internet and postal services will be addressed, as will the regulatory environment for private sector involvement and the development of technology for distance education in priority areas.

8. Urban Management: With Afghanistan's urban population estimated at around 30 percent of the total population, this program aims to create cities as viable economic hubs around the country. The program will address rebuilding in cities destroyed by war, provision of services to housing areas, waste water and sanitation services, new land acquisition for housing as well as attention to policy issues such as town planning and management and standards, procedures and legislation.

9. Energy and Mining: As in other areas, the power and mining sectors have suffered severe neglect after years of war. The energy and mining program, which recognizes the significant role of the private sector in this area, aims to secure cost-effective power supply to urban areas and expansion to rural areas where it is cost-effective and practical. The role of government will focus on regulation of the sector and development of a policy environment for private sector participation rather than direct involvement in operational activities.

10. Natural Resource Management: Focusing on community management of natural resources and improvements in livelihoods, this program will rehabilitate and enhance the development of sustainable agriculture, horticulture and livestock production, including identification of viable substitutes for poppy production. Resource protection measures will include sustainable water usage and protection of existing forests as well as new planting through agro-forestry programs. Additionally, environmental laws and policies will be developed and awareness campaigns conducted to reach out to the population.

11. Trade and Private Investment: Private sector development lies at the heart of the government's development plans, and the trade and investment program will lay the basis for developing an environment conducive to foreign and domestic investment. Activities will include assistance for small business development, efforts to improve governance, creation of laws in areas such as competition, direct and foreign investment and standards and certification. The challenging issues of divestiture of state owned enterprises will also be included in this program.

12. Public Administration: The Public Administration program focuses on three key areas: the establishment of an effective civil service system; rehabilitating the physical infrastructure of government; and developing an organizational structure that permits the government to deliver the needed goods and services to the Afghan public in an effective manner. In addition to physical infrastructure, the program will aim to rationalize the number of ministries, ensure that donor assistance is integrated into the budget process and reduce the number of government corporations. Within this program an important sub-program will focus on mainstreaming gender in public administration.

13. Security and Rule of Law: Numerous specific activities relating to security are covered under this program. To address the rule of law, activities will improve the domestic justice 
system to ensure independence of the judiciary, and will include efforts to rebuild the administration of juvenile justice, prison and law enforcement systems. Among the activities to be carried out are the establishment of new courts and the strengthening of legal aid services within the organizational structure of the Supreme Court. 


\section{BANK GROUP PROGRAM SUMMARY, FY02-FY04 Tentative IDA Grant/Credit Program}

\begin{tabular}{|c|c|c|c|c|}
\hline Fiscal Year & Project & $\begin{array}{c}\text { Project } \\
\text { Volume } \\
\text { Estimates } \\
\text { US\$m }\end{array}$ & $\begin{array}{l}\text { IA }^{* *} \\
\text { Grants } \\
\text { USSm }\end{array}$ & $\begin{array}{c}\text { DA } \\
\text { Credits } \\
\text { USSm }\end{array}$ \\
\hline \multicolumn{5}{|l|}{ Actual } \\
\hline \multirow[t]{5}{*}{2002} & Emergency Public Administration & 10 & 10 & \\
\hline & Emergency Education & 15 & 15 & \\
\hline & Emergency Infrastructure & 33 & 33 & \\
\hline & $\begin{array}{l}\text { Emergency Community Empowerment and } \\
\text { Public Works }\end{array}$ & 42 & 42 & \\
\hline & Subtotal: & 100 & 100 & $\mathbf{0}$ \\
\hline \multicolumn{5}{|l|}{ Planned* } \\
\hline \multirow[t]{5}{*}{2003} & Emergency Transport/Roads & 108 & & 108 \\
\hline & Health Sector Emergency Rehabilitation & $15-60$ & 30 & \\
\hline & Emergency Public Administration II & 10 & 10 & \\
\hline & National Emergency Employment II (Standby) & $25-100$ & 20 & 32 \\
\hline & Subtotal: & & 60 & 140 \\
\hline \multirow[t]{7}{*}{2004} & Financial Sector & $15-30$ & & 20 \\
\hline & Public Sector Reform & $50-100$ & 35 & 65 \\
\hline & Emergency Community Empowerment II & $50-100$ & 35 & 65 \\
\hline & Other projects under consideration: & & & \\
\hline & $\begin{array}{l}\text { Water Resources Management, Urban Land, } \\
\text { Fiscal Rehabilitation }\end{array}$ & & 20 & 30 \\
\hline & Subtotal: & & 90 & 180 \\
\hline & Total FY02-04 \$570m & & 250 & 320 \\
\hline
\end{tabular}

\footnotetext{
*The program is tentative and subject to discussion with Government. Timing of delivery and Government's priorities for investments remain uncertain. Given the continued emergency nature of the program significant changes could be expected.

**Note that grant proportions for FY04 are estimates and could be between $25-40 \%$.
} 


\section{Annex 11 \\ International Finance Corporation's (IFC) Strategy in Afghanistan}

1. The development of the private sector is a key element of Afghanistan's reconstruction strategy. IFC is actively pursuing a program in the country as a part of the overall private sector development efforts of the Bank Group.

2. IFC's strategy in Afghanistan is to focus on the following sectors:

- the financial sector, including SMEs and the establishment of a commercial bank;

- business hotels; and

- potentially telecoms.

3. Key activities to date include:

- IFC is investing up to US\$1.25 million equivalent for a $25 \%$ equity stake in First Microfinance Bank of Afghanistan (FMBA), a micro finance institution with AKFED (presented to the Board of Executive Directors in October 2002).

- Discussions are underway with various parties - the most serious of which is the Agha Khan Foundation (Tourism Promotion Services (TPS)) for the establishment of a business hotel in Kabul. Last year, IFC did preliminary work on this sector and hired a hospitality consultant via USTDA Trust Funds to assess the overall environment for hotel development managers, construction companies, etc. Policy issues have affected the speed at which this project is progressing, however it is moving forward. There is a good opportunity for IFC to play a broker role in putting together all the necessary components to progress the project.

- Discussions are also underway with various parties in the banking and telecoms sectors. IFC is considering various approaches, including working together with FMBA, for the establishment of a commercial bank in Afghanistan. IFC is also pursuing a possible investment in a cellular telephone company.

4. The main impediments for IFC investments in the country are:

- political instability and poor security, especially outside of Kabul (which have spillover effects such as difficulty in obtaining insurance coverage);

- lack of well known and reputable local sponsors;

- low to moderate interest from international companies in investing capital;

- absence of a remittance system (currently funds are remitted via the "hawala" system);

- absence of laws that would facilitate industrial activity and investment (these are in the process of being instituted with assistance from the World Bank and IMF). 